\title{
Advances and Future Directions for Mechanical Circulatory Support
}

\author{
Michelle Capdeville, $\mathrm{MD}^{\mathrm{a}, *}$, Nicholas G. Smedira, MD
}

\section{KEYWORDS}

- Mechanical circulatory support • Ventricular assist device $\bullet$ Axial flow $\bullet$ HeartMate II

- HeartWare

\section{KEY POINTS}

- Second-generation axial flow ventricular assist devices (VADs) have demonstrated increased durability relative to first-generation devices.

- Advantages of second-generation and third-generation VADs include fewer moving parts, smaller size, lower infection rates, and silent operation.

- With the ongoing shortage of donor organs, current generations of VADs show promise as alternatives to transplant in select patients.

- Appropriate risk assessment can assist in the proper selection of VAD candidates.

- Echocardiography is indispensable in the perioperative management of VAD patients.

\section{INTRODUCTION}

Although cardiac transplant remains the gold standard for the treatment of end-stage heart failure, limited donor organ availability and growing numbers of eligible recipients have increased the demand for alternative therapies. This is in spite of the use of older and more high-risk donor hearts, DCD (donors after circulatory determination of death) hearts, ${ }^{1,2}$ and the use of the newer Organ Care System (TransMedics Inc, Andover, MA, USA) "heart-in-a-box" technique, in which the donor heart is perfused at the time of harvest to allow for prolongation of the ischemic time and for acceptance of organs from longer geographic distances. At present, the number of heart transplant operations performed in the United States has remained constant at approximately 2200 per year, and there has been a steady decline in the number of these procedures over the past 15 years. $^{3}$

Following the 2001 landmark publication of the REMATCH trial (Randomized Evaluation of Mechanical Assistance for the Treatment of Congestive Heart Failure),

\footnotetext{
${ }^{a}$ Department of Cardiothoracic Anesthesia, Cleveland Clinic, 9500 Euclid Avenue, J4-331, Cleveland, OH 44195, USA; ${ }^{b}$ Department of Cardiovascular Surgery, Cleveland Clinic, 9500 Euclid Avenue, J4-1, Cleveland, OH 44195, USA

* Corresponding author.

E-mail address: capdevm@ccf.org
} 
which compared optimal medical management to device therapy in nontransplant candidates with end-stage heart failure, it became apparent that mechanical cardiac assist would become a viable alternative in properly selected patients. ${ }^{4}$ The results of the REMATCH trial ultimately led to United States Food and Drug Administration (FDA) approval of the HeartMate XVE (Thoratec Corporation, Pleasanton, CA, USA) for destination therapy in November 2002, followed by approval for Medicare coverage for the same indication in October 2003.

The following sections discuss 2 rotary devices in current use: the HeartMate II (Thoratec Corporation, Pleasanton, CA, USA) and the newer investigational HeartWare HVAD (HeartWare, Inc, Miami Lakes, FL, USA).

\section{SECOND-GENERATION VENTRICULAR ASSIST DEVICES}

The first generation implantable VADs were pulsatile volume displacement pumps. Despite being successful as bridges to transplant, they were limited by several adverse events, including infection, thromboembolism, and mechanical failure.

The introduction of axial flow pumps, which include the HeartMate II, the Jarvik 2000 Flowmaker (Jarvik Heart, Inc, New York, NY, USA), and the MicroMed DeBakey (MicroMed Cardiovascular, Inc, Houston, TX, USA), eliminated several problems encountered with earlier-generation devices. The HeartMate II has been the most successful of these pumps ${ }^{5}$ and received FDA approval for destination therapy in January 2010. The following are its advantages over first-generation devices:

- Fewer moving parts (the rotor is the only moving part)

- Wear-resistant bearings

- Small size and weight, allowing for implantation in smaller patients

- Silent operation

- Decreased power consumption

- More comfortable

- Smaller driveline, resulting in lower infection rates

- Relatively low rate of thromboembolism

- Lack of valves and reservoir chamber, with potentially increased durability

\section{INDICATIONS}

\section{Bridge to Transplant}

VAD support as a bridge to transplant has increased significantly in recent years. Patients awaiting cardiac transplant and who are managed medically may require VAD rescue if their condition deteriorates. In a US study of 3711 United Network for Organ Sharing status 1A patients between January 2000 and December 2006, of whom 2208 were initially medically managed and 1503 were supported with a VAD as a bridge to transplant, $20 \%$ of the medically treated patients went on to require VAD support. VAD support in medically managed status $1 \mathrm{~A}$ patients was associated with a significantly greater probability of survival and/or transplant at 3 months (66.5\%-87.1\% increased probability). This observation has led to the suggestion that earlier/elective institution of VAD support in medically managed status $1 \mathrm{~A}$ patients should be considered in those at greater risk of death or with long expected waiting times for organ availability. ${ }^{6}$ In our center, nearly $40 \%$ of patients are supported with a left ventricular assist device (LVAD) at the time of transplant.

In patients who are not candidates for cardiac transplant because of pulmonary hypertension, some studies have demonstrated a reduction in pulmonary vascular 
resistance (PVR) after an extended period of support with a VAD, thereby allowing eventual transplant eligibility. ${ }^{7}$

\section{Bridge to Recovery}

A limited number of patients with idiopathic cardiomyopathy have demonstrated myocardial recovery after VAD support and were successfully weaned from device therapy. ${ }^{8-10}$ Although the reported incidence of myocardial recovery from reverse remodeling in LVAD-supported patients has been variably low, ${ }^{11}$ there has been ongoing interest in trying to identify some of the mechanisms involved in this process. Unfortunately, prediction of which patients are likely to recover has been elusive because there is no reliable marker of myocardial recovery with VAD support. ${ }^{12}$ Myocardial samples taken at the time of LVAD implant and after explant have demonstrated several changes, including increased expression and responsiveness of myocyte $\beta$-adrenergic receptors and favorable changes in the enzymes that modify the extracellular matrix, as well as calcium cycling proteins. ${ }^{13}$

In a single-center prospective study of 15 patients with end-stage heart failure with nonischemic cardiomyopathy receiving a pulsatile HeartMate I (Thoratec Corporation, Pleasanton, California, USA) LVAD, pharmacologic interventions (lisinopril, carvedilol, spironolactone, and losartan) were initiated during device support with the goal of reversing pathologic hypertrophy, initiating reverse remodeling, and normalizing cellular metabolic function. ${ }^{14}$ Echocardiography was used to determine whether maximal reverse remodeling had occurred, as evidenced by measurements of left ventricular (LV) dimensions with the pump turned off. At this point, the $\beta_{2}$-adrenergic agonist clenbuterol was administered. This protocol allowed for pump removal in approximately two-thirds of patients, with lasting recovery and favorable quality of life. ${ }^{15} \mathrm{~A}$ similar study was conducted by the same investigators in 20 patients who received an axial flow LVAD for nonischemic cardiomyopathy. ${ }^{16}$ The investigators also demonstrated reversal of end-stage heart failure in 12 of these patients, of whom 10 were alive and well at follow-up. Experimentally, clenbuterol has been shown to induce physiologic myocardial hypertrophy in several models of heart failure. ${ }^{17,18}$

The Harefield Recovery Study (HARP) is a multicenter trial that is currently underway in the United States and is examining whether patients with nonischemic cardiomyopathy on LVAD support can recover sufficient myocardial function to allow for pump explantation using clenbuterol.

\section{Bridge to Decision}

Patients with multisystem organ failure and refractory acute cardiogenic shock who undergo permanent LVAD implantation tend to have worse outcomes than patients who have been optimized before implant. ${ }^{19}$ In many of these patients, neurologic status may be in question. Placement of an expensive long-term or permanent device may not be cost-effective. In these situations, placement of a short-term device, such as the Impella Recover (ABIOMED Inc, Danvers, MA, USA), ${ }^{20}$ TandemHeart (Cardiac Assist Inc, Pittsburgh, PA, USA), ${ }^{21}$ or extracorporeal membrane oxygenation, ${ }^{22}$ can stabilize the patient clinically and allow one a greater window of time to decide on the more appropriate course of action, and at a lower cost.

When 1-year survival was assessed in 280 destination therapy HeartMate XVE LVAD patients who were divided into low-, medium-, high-, and very high risk groups based on a composite risk score, the higher-risk groups had significantly worse survival outcomes $\left(81 \%, 62 \%, 28 \%\right.$, and $11 \%$, respectively). ${ }^{19}$ This led to the recommendation that very-high-risk patients be bridged to decision with a short-term device. 


\section{Destination Therapy}

Following the favorable results of the REMATCH trial and with the ongoing shortage of donor hearts, destination therapy is becoming a viable option for a large number of patients with end-stage heart failure. The REMATCH trial set the stage for the future of destination therapy. In this study, 1-year survival was $52 \%$ in the LVAD group compared with $25 \%$ in the medically treated group, and 2 -year survival was $28 \%$ in the LVAD group compared with $8 \%$ in medically managed patients. ${ }^{4}$ LVAD patients who were recruited in the second half of the study had significantly better survival than patients recruited in the earlier study period, likely because of improved experience and management, as well as device modifications. ${ }^{23}$

The INTrEPID study (Investigation of Nontransplant-Eligible Patients who are Inotrope Dependent), which was a US-Canadian destination therapy trial that compared patients receiving the Novacor LVAS (World Heart Corporation, Oakland, CA, USA) to optimal medical management, showed 6-month survival rates of $46 \%$ and $22 \%(P=.03)$, respectively, and 12 -month survival rates of $27 \%$ and $11 \%$ $(P=.02)$. There was, however, a significant rate of neurologic events in the VAD cohort $(62 \%)$ compared with medically managed patients $(11 \%){ }^{24}$

\section{CONTRAINDICATIONS}

With the increasing experience and success of destination therapy, many of the contraindications that were once considered absolute are now relative. The contraindications to VAD implantation are outlined in Table 1.

\section{RISK ASSESSMENT}

Operative mortality is greatly influenced by severity of functional impairment, endorgan dysfunction, nutritional status, and global markers of cardiac dysfunction (low pulmonary artery pressures (PAP) and elevated levels of liver enzymes from hepatic congestion). ${ }^{19}$ Risk assessment is an important tool in the appropriate selection of candidates for VAD therapy and enables clinicians to provide patients and families with realistic expectations, particularly with regard to decisions about destination therapy.

\section{INTERMACS}

INTERMACS, the Interagency Registry for Mechanical Assisted Circulatory Support, is an elective registry that follows-up patients with long-term FDA-approved mechanical

\begin{tabular}{|ll|}
\hline Table 1 & \\
Contraindications to VAD implantation & \\
Relative & Absolute \\
\hline Mechanical AVR & Irreversible end-organ damage \\
\hline Active malignancy & Poor neurologic status \\
\hline Morbid obesity & Ongoing coagulopathy \\
\hline- & Sepsis \\
\hline- & Social issues \\
\hline- & Substance abuse \\
\hline- & Noncompliance \\
\hline
\end{tabular}

Abbreviation: AVR, aortic valve replacement. 
circulatory support devices in the United States, and has identified patient profiles and defined appropriate timelines for initiating VAD support. ${ }^{25-27}$ Using data from the INTERMACS registry ${ }^{28}$ patients have been risk stratified into 7 categories (Table 2) based on their condition at presentation for VAD implantation.

Data from INTERMACS has shown that preimplantation condition has a significant impact on patient survival and highlights the importance of early referral before cardiogenic shock and irreversible end-organ damage occur. ${ }^{29}$ Patients in the higher-risk categories have been shown to have increased short-term morbidity and mortality, whereas data for outcomes of patients in INTERMACS levels 4 to 7 are still lacking.

\section{LIETZ-MILLER RISK SCORE}

Surgical risk has been estimated in pulsatile pumps using the Lietz-Miller Destination Therapy Risk Score (DTRS), which uses a point system assigned to clinical and laboratory variables, and bases mortality risk after VAD implantation on point totals. Patients with the highest point scores were shown to have estimated 1-year survival rates of only $11 \%$ post-LVAD implant, highlighting the importance of proper patient selection to maintain acceptable outcomes. ${ }^{19}$ Significant prognosticators for in-hospital mortality included hematologic abnormalities, poor nutritional status, markers of end-organ dysfunction and right ventricular (RV) dysfunction, and lack of inotropic support.

When the DTRS was studied in patients receiving a continuous flow LVAD, the score was able to discriminate between patients with high and low 3-month in-hospital mortality but failed to discriminate between low- and medium-risk groups. ${ }^{30}$ In bridge-to-transplant patients, the DTRS was a poor predictor of 2-year mortality, whereas in destination therapy patients, the score was able to stratify outcomes over 2 years but was unable to distinguish patients with a futile outcome.

\begin{tabular}{|c|c|c|c|}
\hline \multicolumn{4}{|c|}{$\begin{array}{l}\text { Table } 2 \\
\text { INTERMACS risk stratification }\end{array}$} \\
\hline Profile\# & Description & Definition & Time to MCS \\
\hline 1 & Crashing and burning & Critical cardiogenic shock & Within hours \\
\hline 2 & Progressive decline & $\begin{array}{l}\text { Inotrope dependence with } \\
\text { continuing deterioration }\end{array}$ & Within a few days \\
\hline 3 & $\begin{array}{l}\text { Stable but inotrope } \\
\text { dependent }\end{array}$ & $\begin{array}{l}\text { Clinically stable on mild-to-moderate } \\
\text { doses of intravenous inotropes } \\
\text { (includes stable patients on } \\
\text { temporary circulatory support } \\
\text { without inotropes) }\end{array}$ & Within a few weeks \\
\hline 4 & $\begin{array}{l}\text { Recurrent advanced } \\
\text { heart failure }\end{array}$ & $\begin{array}{l}\text { "Recurrent" rather than "refractory" } \\
\text { decompensation }\end{array}$ & $\begin{array}{l}\text { Within weeks to } \\
\text { months }\end{array}$ \\
\hline 5 & Exertion intolerant & Comfortable at rest & Variable \\
\hline 6 & Exertion limited & $\begin{array}{l}\text { Able to do some mild activity; } \\
\text { fatigued within a few minutes of } \\
\text { any meaningful physical exertion }\end{array}$ & Variable \\
\hline 7 & Advanced NYHA III & $\begin{array}{l}\text { Clinically stable with a reasonable } \\
\text { level of comfortable activity, } \\
\text { despite nonrecent history of } \\
\text { previous decompensation }\end{array}$ & $\begin{array}{l}\text { Not a candidate } \\
\text { for MCS }\end{array}$ \\
\hline
\end{tabular}

Abbreviations: MCS, mechanical circulatory support; NYHA, New York Heart Association. 


\section{MATTHEWS RISK SCORE}

Matthews and colleagues ${ }^{31}$ developed a right ventricular risk score (RVRS) to determine short-term risk of RV failure and postoperative mortality in destination therapy patients. The investigators found that independent predictors of RV failure included vasopressor requirement (4 points), aspartate aminotransferase levels of $80 \mathrm{IU} / \mathrm{L}$ or more (2 points), bilirubin levels greater than $2.0 \mathrm{mg} / \mathrm{dL}$ ( 2.5 points), and creatinine levels of $2.3 \mathrm{mg} / \mathrm{dL}$ or more (3 points). Odds ratios for RV failure were as follows: RVRS $\leq 3.0,4.0-5.0$, and $\geq 5.5 ; 0.49$ (95\% confidence interval [Cl] 0.37-0.64), 2.8 (95\% Cl 1.4-5.9), and 7.6 (95\% Cl 3.4-17.1), respectively. The 180-day survival was $90 \pm 3 \%, 80 \pm 8 \%$, and $66 \pm 9 \%$, respectively.

\section{PHYSIOLOGY OF AXIAL FLOW}

With axial flow pumps, there is continuous unloading throughout the cardiac cycle. Concerns over the effects of reduced or absent pulsatility on organs such as the brain, gastrointestinal (Gl) tract, and kidneys as well as endocrine effects have been raised with the use of rotary cardiac assist devices. Much of our current understanding comes from animal data, although increasing information from human patients with heart failure is slowly emerging.

Rotary pumps are capable of generating a full cardiac output; however, even small amounts of ventricular recovery result in a certain degree of pulsatility. ${ }^{32}$ With increasing myocardial recovery, pulsatility increases and can be seen on the arterial waveform. A flat arterial trace is only seen when the pump is run at maximal speeds, which is not recommended (see below). ${ }^{33}$ In most patients, pulsatility ranges between 5 and $25 \mathrm{~mm} \mathrm{Hg}^{34}$

Reduced pulsatility from continuous flow LVADs was shown in a calf model to induce severe periarteritis in the kidneys, because of upregulation of the local reninangiotensin system in inflammatory cells. ${ }^{35}$ Angiotensin II type 1 receptors, which play a role in cell growth and proinflammatory and profibrogenic activity, and angiotensin-converting enzyme were upregulated in renal mononuclear inflammatory cells.

Changes in aortic and arterial wall structure, including the renal artery have been described with continuous flow. ${ }^{36,37}$ In the kidney, renal cortical hypertrophy and infiltration of inflammatory cells into the renal cortex were reported. The aortic wall in goats showed thinning and atrophic changes, with a reduced volume ratio of smooth muscle cells.

There has been some concern that low pulsatility might create areas of stasis distal to an existing stenosis, potentially leading to thrombosis. Frazier and colleagues ${ }^{38}$ described thrombosis of a major branch artery in the presence of a $30 \%$ stenosis and full anticoagulation in patients in whom the LVAD outflow conduit was placed in the descending aorta.

Thrombosis of the aortic root has been rarely reported and is believed to be due to blood stasis and prolonged closure of the aortic valve. Laminated thrombus has been observed more frequently in the area of the noncoronary cusp, perhaps because of the lack of coronary flow relative to the other cusp areas.

Commissural fusion of the aortic valve has been noted with both pulsatile and axial flow devices. ${ }^{39}$ In the case of axial flow pumps, commissural fusion has been thought to be related to mild-to-moderate degrees of continuous aortic insufficiency (Al).

It is generally believed that long-term nonpulsatile flow does not affect cerebral autoregulation. ${ }^{40}$ At least in clinical practice, no major adverse effects have been observed. 
Hemolysis has not been shown to be a clinically relevant event in patients supported with axial flow devices unless it is associated with pump thrombosis.

Bleeding from intestinal arteriovenous malformations (AVMs) is a complication that has been recognized with axial flow pumps. These AVMs are typically incidental findings in normal adults, but bleeding from these sites may be worsened by anticoagulation. ${ }^{41}$ In a retrospective review of 33 patients receiving a long-term LVAD between June 1, 2006, and July 31, 2008, 40\% of HeartMate II recipients $(n=20)$, experienced at least 1 episode of Gl bleeding, whereas the remaining patients who had received pulsatile pumps had no reported episodes of Gl bleeding. ${ }^{42}$ In $65 \%$ of the bleeding episodes observed, no definite source could be identified. The investigators suggested that this bleeding might be due to angiodysplasias in the small bowel, as has been described in patients with aortic stenosis (AS). ${ }^{43}$ This phenomenon is often referred to as Heyde syndrome, after the original description by Heyde in 1958. ${ }^{44}$ This type of bleeding has been shown to resolve in patients with AS after valve replacement. ${ }^{45}$ An association between shear-stress-induced acquired von Willebrand disease type $2 \mathrm{~A}$ and bleeding from $\mathrm{Gl}$ angiodysplasias in patients with $\mathrm{AS}$ has been suggested. ${ }^{46,47}$ In one report, HeartMate II recipients were shown to be lacking the large von Willebrand factor (vWF) multimers, suggesting that the device might induce acquired von Willebrand disease. ${ }^{48,49}$ Blood exposure to high sheer stress seems to be the common denominator in acquired von Willebrand disease in patients with AS and LVAD patients. Removal of the source of high shear stress has relieved the bleeding problems in both groups of patients. ${ }^{50}$

In a study of 26 patients who had received a HeartMate II device, vWF multimer assays were performed both with the device in place and postexplant for transplant. The investigators found that while on device support, all patients showed severely impaired platelet aggregation and loss of large vWF multimers. After device removal, normal platelet aggregation patterns and normal multimer analysis were noted, confirming that this hematologic abnormality is reversible. ${ }^{51}$

Despite the recognition of acquired von Willebrand disease in assist device patients, the importance of this condition remains uncertain.

\section{HEARTMATE II}

The HeartMate II has been the most successful of the second-generation axial flow rotary devices, and is approved both as a bridge to transplant and destination therapy (Figs. 1-3). ${ }^{5}$ HeartMate II is a valveless axial flow pump with a titanium-coated rotor. This device has an implant volume of $63 \mathrm{~mL}$, weighs $350 \mathrm{gm}$, and can generate flows between 3 and $10 \mathrm{~L} / \mathrm{min}$ at pump speeds of 6000 to $15,000 \mathrm{rpm}$. As with firstgeneration devices, the inflow cannula is located at the LV apex and the outflow cannula is anastomosed to the ascending aorta. Both inflow and outflow cannulas are made of woven Dacron and require preclotting. The actual pump is implanted preperitoneally (most commonly) or intraabdominally. The pump's internal rotor has helical blades that curve around a central shaft. As the rotor spins, kinetic energy causes the blood to be drawn from the LV apex in a continuous manner. The motor is located within the pump housing and generates a spinning magnetic field that causes the rotor to spin. A tunneled percutaneous lead that is attached to a controller supplies power and control to the device. The percutaneous lead can be connected to a pair of rechargeable batteries worn by the patient or to an external power module. The absence of a blood sac has eliminated the need for venting, with a resultant reduction in the size of the driveline relative to first-generation devices. The HeartMate II received FDA approval as a bridge to transplant in April 2008. 


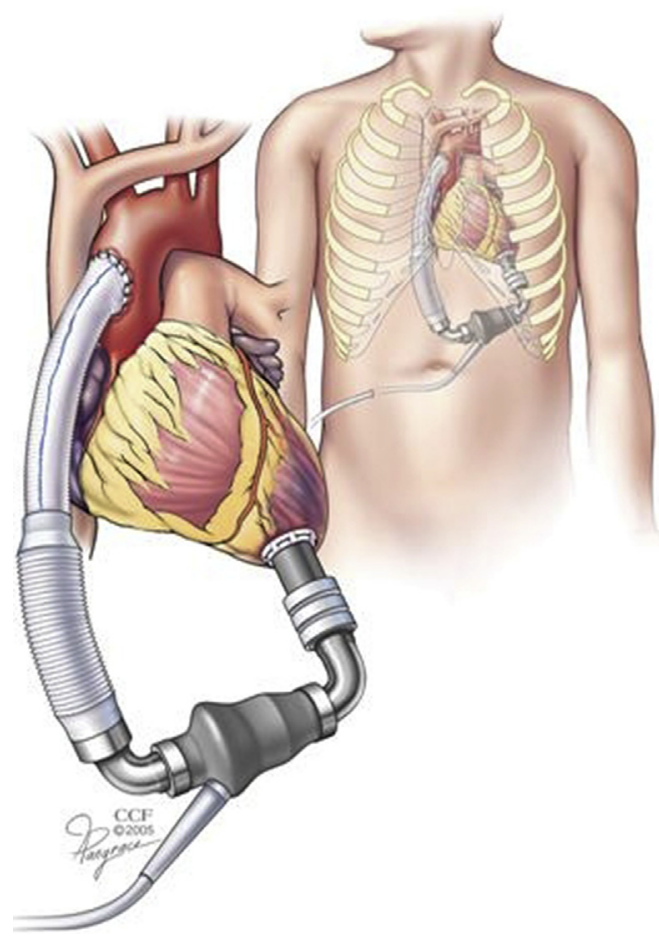

Fig. 1. HeartMate II LVAD in situ. Left ventricular inflow cannula is located at LV apex; outflow cannula is anastomosed to the ascending aorta.

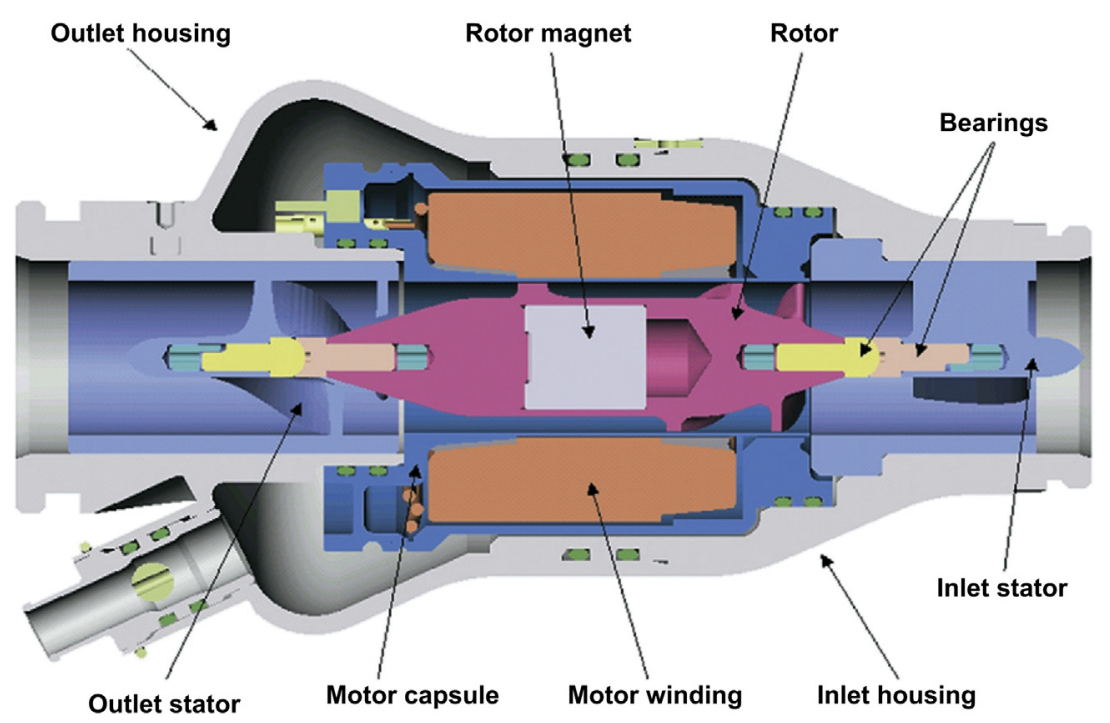

Fig. 2. HeartMate II axial flow pump showing titanium-coated internal rotor. (Courtesy of Thoratec Corporation, Pleasanton, CA, USA.) 


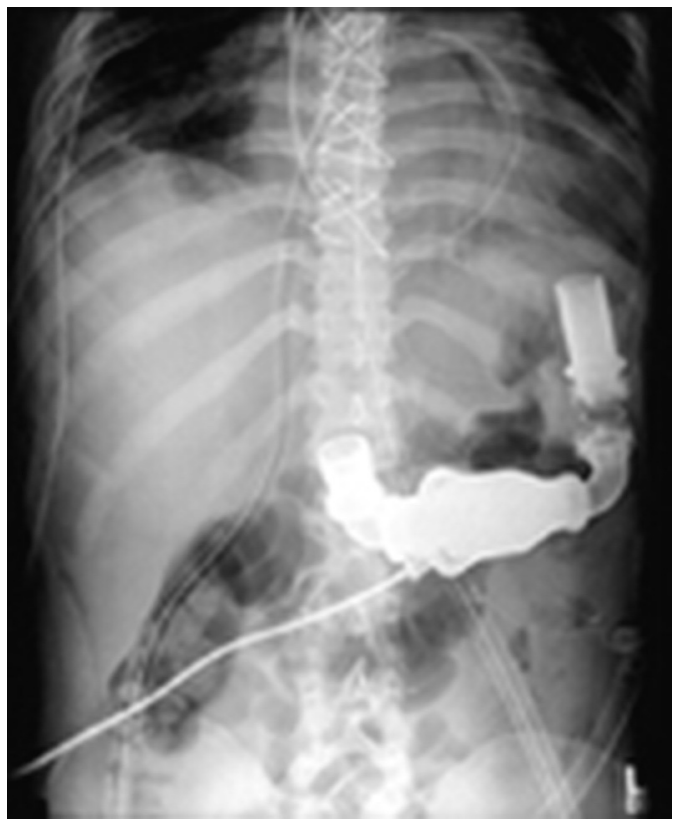

Fig. 3. Chest radiograph showing HeartMate II LVAD in situ. (Courtesy of Thoratec Corporation, Pleasanton, CA, USA.)

Anticoagulation consists of heparin initially, followed by transition to warfarin, with a targeted international normalized ratio (INR) between 1.5 and 2.5 , and aspirin (early on, patients were more vigorously anticoagulated with a target INR 2.5-3.5). Dipyridamole has been removed from the original standard regimen. This anticoagulation regimen is in contrast to the HeartMate I, for which only aspirin was required. ${ }^{52}$

In a prospective US multicenter study of 133 transplant candidates who underwent implantation of the HeartMate II LVAD, the 6-month survival was $75 \%$ and the 12-month survival was $68 \% .{ }^{53}$ New York Heart Association (NYHA) functional classification and 6-minute walk test performance were significantly improved at 3 months, as were quality of life measures using the Minnesota Living with Heart Failure and Kansas City Cardiomyopathy measures. The most common complication was bleeding. Device-related infection occurred in $14 \%$ of patients and was limited to the driveline. The incidence of stroke was $8 \%$ (6\% ischemic and $2 \%$ hemorrhagic). Hemolysis occurred in $3 \%$ of patients. About $4 \%$ required device replacement.

The HeartMate II Destination Therapy Trial compared the HeartMate II to the older HeartMate XVE. ${ }^{5}$ In this study, the primary end point was survival without disabling stroke and without the need to repair or replace the device. About $46 \%$ of patients in the HeartMate II group reached the primary end point, compared with $11 \%$ $(P<.001)$ in the HeartMate XVE group. These results were primarily due to improved durability of the axial flow pump, with only $10 \%$ of patients requiring pump replacement.

\section{Pump Function and Settings}

The speed of the rotor and the pressure gradient across the pump determine the pump performance. Simply stated, flow and pressure are inversely related. This 
pressure-flow relationship has been measured at different rotor speeds as illustrated in Fig. 4. As resistance is increased, there comes a critical point at which the pump will shut off and flow equals 0 .

Throughout the cardiac cycle, the pressure differential between inlet and outlet cannulas is equal to the aortic pressure minus the LV pressure, plus a combined pressure loss across the inlet and outlet cannulas. ${ }^{54}$ Because this system is devoid of valves, sufficient pump speeds must be generated to prevent reverse flow that could potentially result from pressure differentials that are lower than the expected aortic pressures.

These pumps are capable of generating relatively high negative pressures at the inlet conduit, which can lead to ventricular collapse (see below). Generation of negative pressure can occur when LV preload is less than that needed for the pump at any set speed or when there is inflow obstruction, as can occur with thrombosis or improper positioning of the inlet cannula.

There are 4 pump parameters that provide important information about LVAD function. Each parameter depends on the patient's clinical condition, and changes in baseline values and trends tend to be more important than the actual numbers themselves.

- Pump speed: In general, pump speed is set to maintain a degree of pulsatility during the cardiac cycle. The greatest flow occurs during systole, when the pressure differential across the pump is least, and minimum flow occurs during diastole, when inlet pressures are lowest and the pressure difference is greater. At specific pump speeds, there is an inverse relationship between flow and the pressure differential (aortic pressure minus LV pressure) across the pump. ${ }^{55} \mathrm{At}$ maximum pump speed, the LV volume is at its lowest and the LV does not contribute to the cardiac output. At lower pump speeds, there is more blood in the ventricle and systemic flow becomes pulsatile (LV systolic pressure exceeds aortic pressure, allowing the valve to open). The optimum speed is assessed with echocardiography and the following are established: no septal shift, normal LV size, adequate cardiac index, and intermittent opening of the aortic valve. A typical speed range is on the order of 8600 to $9800 \mathrm{rpm}$.

- Pulsatility index (PI): The PI is defined as the difference between maximum and minimum flow divided by the average flow during the cardiac cycle: $\mathrm{PI}=\left(Q_{\max }-Q_{\min }\right) / Q_{\mathrm{avg}}$. PI is a dimensionless number with values ranging between

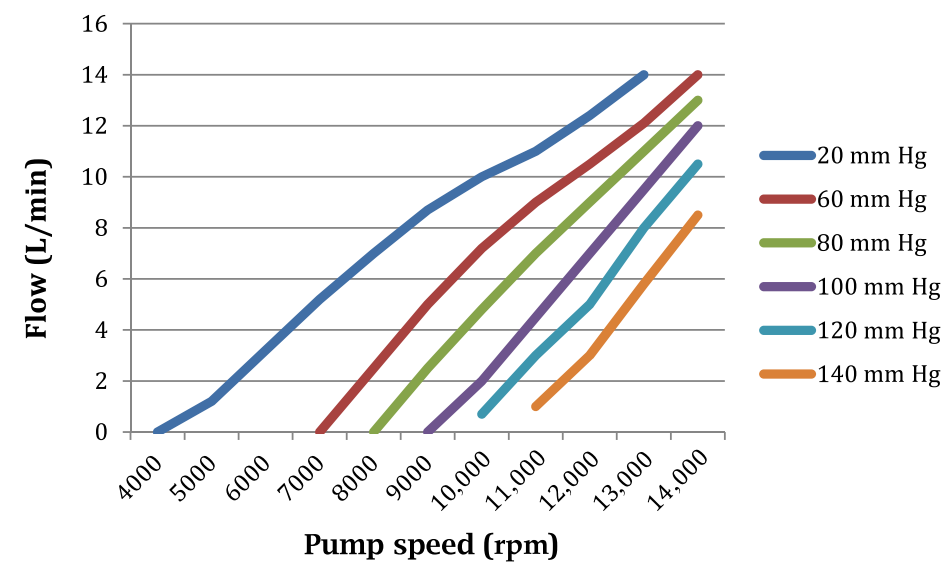

Fig. 4. Graphic illustration of pressure-flow relationship at various pump speeds. 
1 and 10 (typical ranges seen clinically are between 3 and 4). PI is inversely related to the amount of pump support. With severely reduced LV contractility, minimal pulsatility (low PI) is observed. A low PI can also be seen in patients with better contractility, but in the presence of excessive pump speeds resulting in ventricular collapse. With hypovolemia, there is a fall in PI without a corresponding increase in pump speed. An increase in PI can be seen with increased contractility and ventricular pressure (ie, myocardial recovery, inotrope support, increased volume status).

- Power: Pump power, measured in Watts, reflects the motor's voltage and current. The power range with this device is between 0 and $25.5 \mathrm{~W}$. The system controller measures power directly. Power at a specified speed and estimated flow are related. Increased power can be due to increases in pump flow, pump speed, or physiologic demand. When there is an increase in power that is unrelated to increased flow, as can be seen in the presence of pump thrombus, falsely elevated flow readings will be seen. There is an expected range of power for each set speed under normal operating conditions. Power values that fall outside of this range are displayed as +++ or --- instead of numerically when the estimated flow is above or below the expected limits at a specific set speed.

- Estimated flow: Flow rate, as seen on the system module, is an estimate and not a precise measurement. The flow rate is determined by power and pump speed. At a given pump speed, the relationship between power and flow tends to be linear, with the exception of very high or very low pump speeds. As LVAD preload and LV pressure increase, flow increases. As LVAD afterload and aortic pressure decrease, flow also increases. Flows should be maintained at greater than 3.0 L/min. Because this is a calculated value, at higher and lower ends of the power-flow relationship, this number becomes less reliable. Pump flows may overestimate and underestimate true flow by $500 \mathrm{~mL}$. Increases in power that are not matched by an increase in flow are suspicious for pump thrombus. Decreases in power and estimated flow can be due to inflow cannula obstruction or suction.

\section{SURGICAL CONSIDERATIONS Patient Selection}

Proper patient selection has a significant impact on surgical outcomes. Several scoring systems described above have been developed to better predict which patients will survive with medical management and which patients are more likely to have a favorable outcome after LVAD implant. Earlier implementation of mechanical support can prevent or lessen progressive end-organ dysfunction, particularly when prolonged waiting times are anticipated for a donor organ, and is an important part of the selection process. Specific considerations include:

- Nutritional status: Cachexia with a body mass index (BMI), calculated as the weight in kilograms divided by height in meters square, less than $22 \mathrm{~kg} / \mathrm{m}^{2}$ has a high associated perioperative mortality that is frequently related to infection. ${ }^{56}$ This risk factor is potentially modifiable, and aggressive nutritional support should be instituted with specialty care providers. ${ }^{57}$

- Infection: Active infection must be controlled before device implant because this is a primary cause of morbidity and mortality.

- Right ventricular dysfunction: The increased venous return to the right side of the heart that occurs with LVAD support may worsen preexisting RV dysfunction. Leftward shift of the interventricular septum may also alter RV geometry, leading 
to tricuspid regurgitation. ${ }^{58-60}$ Optimization of RV function may include central venous pressure (CVP) reduction (to $15 \mathrm{~mm} \mathrm{Hg}$ or less) with diuresis to reduce $\mathrm{RV}$ workload, which helps reduce hepatic congestion and associated coagulation abnormalities. Elevated PVR should be managed pharmacologically with vasodilators (eg, sildenafil, prostaglandins) and inotropes (milrinone, dobutamine) as deemed appropriate.

- Ventilatory support: Preoperative ventilator support has been shown to be an independent predictor of RV failure. ${ }^{61}$ Diuresis or hemofiltration may improve pulmonary function that is secondary to fluid overload.

- Coagulation status: Clotting abnormalities may be due to use of anticoagulants and antiplatelet agents or may be secondary to hepatic dysfunction. These medications should be discontinued preoperatively whenever possible. Patients on coumadin should be transitioned to heparin and can be treated with vitamin $\mathrm{K}$ and/or fresh frozen plasma.

- Hematologic abnormalities: Patients with low platelet counts should be tested for heparin-induced thrombocytopenia. If they test positive for this abnormality, alternative anticoagulation strategies will be required (ie, bivalirudin) for cardiopulmonary bypass. Sources of anemia should be investigated because this is a risk factor for poor outcomes.

- End-organ dysfunction: Renal, hepatic, pulmonary, and Gl dysfunction should be optimized. A glomerular filtration rate less than $0.5 \mathrm{~mL} / \mathrm{kg} / \mathrm{min}$ is associated with poor outcomes. ${ }^{62}$ Measures to help improve renal perfusion and reduce CVP should be instituted. Hepatic dysfunction that is secondary to RV dysfunction should be managed with preload and afterload reduction. In some instances, ultrafiltration may be beneficial. Pulmonary dysfunction in the presence of heart failure is difficult to assess with accuracy, and pulmonary function tests are not always helpful. Preoperative mechanical ventilation is a strong predictor of poor outcome. ${ }^{63}$ Active Gl bleeding should be thoroughly investigated and managed accordingly.

\section{ANESTHETIC MANAGEMENT}

Anesthetic management of the patient with end-stage heart failure undergoing LVAD implantation has been well described and is beyond the scope of this article. ${ }^{64-68}$ General considerations before cardiopulmonary bypass are outlined in Table 3. Postbypass concerns include the following:

- Right ventricular failure: RV failure is one of the most challenging problems encountered postbypass. RV failure can be difficult to predict and is incompletely understood. Typically, it manifests as elevated CVP, poor LV filling, and reduced LVAD output. Perioperative RV failure is associated with a relatively high mortality in the LVAD recipient, ranging from $19 \%$ to $43 \%,{ }^{69-71}$ and posttransplant survival tends to be worse. ${ }^{72,73}$ Postimplant, the pathophysiology of RV failure is complex and may include increased RV afterload, primary RV myocardial dysfunction, RV ischemia, and ventricular interdependence.

Low preoperative RV stroke work index (RVSWI), a correlate of RV contractility, plays a role in predicting RV dysfunction. RVSWI allows quantification of the ability of the RV to generate pressure and is given by [(mean PAP-mean CVP) $\times$ SVI]/BSA (SVI is the stroke volume index and BSA is the body surface area). In pulsatile LVADs, low RVSWI predicted the need for prolonged inotrope use. ${ }^{74}$ An RVSWI less than $300 \mathrm{~mm} \mathrm{Hg} / \mathrm{mL} / \mathrm{m}^{-2}$ is a strong predictor of the need for right ventricular assist device 


\begin{tabular}{|c|c|}
\hline \multicolumn{2}{|c|}{$\begin{array}{l}\text { Table } 3 \\
\text { Prebypass anesthetic concerns }\end{array}$} \\
\hline Overall Patient Stability & Elective vs Salvage Case \\
\hline Monitoring & $\begin{array}{l}\text { Standard ASA monitors, arterial line (cannulation strategy will } \\
\text { determine proper placement site), pulmonary artery catheter, } \\
\text { multiple large bore intravenous access, TEE }\end{array}$ \\
\hline Ventilatory status & Intubated vs not intubated; ventilator settings \\
\hline Reoperation status & $\begin{array}{l}\text { Will require additional blood and blood products; check antibody } \\
\text { status }\end{array}$ \\
\hline Current symptoms & Can patient lay flat? \\
\hline Anticoagulation status & $\begin{array}{l}\text { Heparin (may require higher heparin doses, FFP or recombinant } \\
\text { AT III if AT III deficient); Coumadin (may require FFP and } \\
\text { vitamin K for reversal) }\end{array}$ \\
\hline Current support & IABP, ECMO, short-term VAD, inotropes \\
\hline Preoperative medications & $\begin{array}{l}\text { Inotropes, vasodilators, diuretics, ACE inhibitors, anticoagulants, } \\
\text { platelet inhibitors, antiarrhythmic medications }\end{array}$ \\
\hline Cause of heart failure & Ischemic, idiopathic, viral (may affect degree of RV preservation) \\
\hline Hematologic & $\begin{array}{l}\text { Anemia (consider cause); thrombocytopenia (rule out heparin- } \\
\text { induced thrombocytopenia); alternative anticoagulation } \\
\text { strategy such as bivalirudin may be needed if patient tests } \\
\text { positive for HIT }\end{array}$ \\
\hline Systemic disease & $\begin{array}{l}\text { Renal, hepatic, pulmonary function (may affect drug } \\
\text { pharmacokinetics and drug dosing) }\end{array}$ \\
\hline Right-sided heart failure & $\begin{array}{l}\text { Hepatic engorgement and tricuspid regurgitation can lead to } \\
\text { passive hepatic congestion and coagulopathy }\end{array}$ \\
\hline Pulmonary hypertension & Can adversely affect right-sided heart function postbypass \\
\hline Infection & $\begin{array}{l}\text { Current antibiotic regimen should be continued per consultant } \\
\text { recommendations }\end{array}$ \\
\hline Pacemaker, AICD & $\begin{array}{l}\text { When present, pacemakers should be interrogated and } \\
\text { programed appropriately for the operating room; AICDs should } \\
\text { be turned off and Zoll pads (Zoll Medical Corporation, } \\
\text { Chelmsford, MA) applied to the patient }\end{array}$ \\
\hline
\end{tabular}

Abbreviations: $\mathrm{ACE}$, angiotensin converting enzyme; $\mathrm{AICD}$, automatic implantable cardioverterdefibrillator; ASA, American Society of Anesthesiologists; AT III, antithrombin III; ECMO; extracorporeal membrane oxygenation; FFP, fresh frozen plasma; HIT, heparin-induced thrombocytopenia; IABP, intra-aortic balloon pump; TEE, transesophageal echocardiography.

support. ${ }^{72}$ In the presence of elevated preoperative PAP and normal CVP (ie, high RVSWI), the risk of postimplant RV failure is low. On the other hand, low PAP may reflect significant $\mathrm{RV}$ dysfunction and the inability to generate sufficient pressure across the pulmonary circuit.

A transpulmonary gradient greater than $16 \mathrm{~mm} \mathrm{Hg}$ in the presence of a central venous pressure greater than or equal to $20 \mathrm{~mm} \mathrm{Hg}$ has a relatively high sensitivity and specificity for predicting post-LVAD RV dysfunction. ${ }^{75}$ Nonhemodynamic preoperative factors may be better predictors of $\mathrm{RV}$ failure than actual functional measurements. ${ }^{73}$

Intraoperative causes of RV failure include air embolism down the right coronary artery, which is seen as ST segment elevations in the inferior leads and ischemic changes in the right coronary territory, and is typically reversible with supportive management (increasing coronary perfusion pressure) with or without reinstituting cardiopulmonary bypass. Intracardiac air may or may not be evident on transesophageal 
echocardiography (TEE). If the right coronary artery is diseased, revascularization may be necessary.

When RV failure is due to preexisting RV dysfunction and does not improve with LV unloading, inotropic or mechanical support may be indicated. Inhaled nitric oxide and inhaled epoprostenol (Flolan) may reduce PAPs sufficiently to improve RV function. ${ }^{76}$

High pump speeds can have a negative effect on RV function by causing septal shift and altering RV geometry. Tricuspid regurgitation can also result.

The need to transfuse large volumes of blood and blood products to treat coagulopathy can lead to RV volume overload with resultant failure. The RV, being thin walled, is particularly vulnerable to volume overload and elevations in PVR. All volume administration should be done judiciously, and trends in CVP should be noted. Pulmonary hypertension can be related to hypoxemia, hypercarbia, elevated airway pressures, and acidosis. Interestingly, in the presence of normal PVR and decompression of the left side of the heart, moderate elevations in CVP may be adequate to generate blood flow across the pulmonary circuit, even in the presence of moderate-to-severe RV dysfunction. ${ }^{77}$ In fact, patients in ventricular fibrillation have been reported to tolerate this arrhythmia with LVAD support. ${ }^{78}$

- Vasoplegia: Chronic vasodilator or inodilator use preoperatively, along with prolonged cardiopulmonary bypass times can result in profound vasoplegia postbypass. Agents such as norepinephrine, vasopressin, ${ }^{79}$ and sometimes methylene blue $^{80}$ may be required to maintain adequate afterload conditions.

- Hypothermia: Hypothermia can worsen coagulopathy, increase metabolic rate with shivering, delay emergence from anesthesia, and lead to arrhythmias. Patients should be adequately rewarmed before separation from cardiopulmonary bypass, and warming measures should include fluid warmers, heated respiratory circuits, warm operating room ambient temperature, and forced air warming devices.

- Coagulopathy: Management of postpump coagulopathy can be challenging because administration of large volumes of blood and blood products can lead to volume overload and RV failure. First and foremost, prevention is essential and includes minimizing pump time, excellent surgical hemostasis, and maintenance of normothermia. Use of aminocaproic acid may help reduce bleeding. Early administration of platelets and fresh frozen plasma is encouraged when indicated. Clotting parameters should be checked at regular intervals. When available, thromboelastography can help to guide product administration. In instances of uncontrolled coagulopathy, there are reports of recombinant factor VII being used (off label) successfully. ${ }^{81,82}$ There are, however, real concerns about the potential risk for thrombosis. In a retrospective study of 62 LVAD patients who received recombinant factor VII, patients were divided into lowdose $(10-20 \mu \mathrm{g} / \mathrm{kg})$ and high-dose $(30-70 \mu \mathrm{g} / \mathrm{kg})$ groups. Patients in the highdose group had a significantly higher incidence of serious thromboembolic events $(36.7 \%$ vs $9.4 \%, P \leq .001) .{ }^{83}$ The risks and benefits of factor VII administration should be discussed with the surgical team, and strong consideration should be given to using lower doses.

- Arrhythmias: Arrhythmias may be related to suction events.

- Target mean arterial pressure: A target mean arterial pressure (MAP) of 70 to $80 \mathrm{~mm} \mathrm{Hg}$ is desirable. A MAP greater than $90 \mathrm{~mm} \mathrm{Hg}$ can lead to reduced pump output because this is an afterload-dependent system. Pump speed should therefore not be titrated to the desired blood pressure. 
- Target pulse pressure: A pulse pressure of 10 to $20 \mathrm{~mm} \mathrm{Hg}$, with intermittent aortic valve opening (approximately every 3 beats), allows for a good balance between pump speed and LV pressure. It is unclear what the optimum frequency of aortic valve opening is. It is thought that aortic valve opening can reduce the risk of aortic valve thrombosis and aortic valve fusion over time. ${ }^{84}$ The pulse pressure is determined by contractility, preload, and pump speed. At high pump speeds, diastolic pressure increases without much change in systolic pressure and pulse pressure decreases.

- Volume status

- Pulse oximetry: In the absence of pulsatility, pulse oximetry is unreliable, and frequent blood gas monitoring is recommended.

Separation from cardiopulmonary bypass is a coordinated exercise between the surgeon, perfusionist, anesthesiologist, and the individual who is adjusting the parameters on the pump module. The following events are essential for effective separation from cardiopulmonary bypass:

- Proper deairing of the heart and cannulas. TEE is used to guide deairing procedures as volume is added to the heart.

- The pump is activated at a fixed speed (generally 8000-9000 rpm) while still on partial bypass.

- Cardiopulmonary bypass flows are gradually reduced as volume is added to the heart, paying close attention to RV function, midline interventricular septal position, and LV volume status. Adequate preload is essential to providing adequate pump output. Ventricular collapse and septal shift may be due to inadequate preload or poor RV performance. LV dilatation can be due to improper inflow cannula position or very high afterload. Excessive afterload can result in reduced pump output because this is an afterload-dependent system. A MAP between 70 and $80 \mathrm{~mm} \mathrm{Hg}$ is generally optimal.

\section{ROLE OF TRANSESOPHAGEAL ECHOCARDIOGRAPHY}

TEE is an indispensable tool in the LVAD patient. It provides real-time assessment of ventricular function, valvular pathology, and hemodynamics in a relatively noninvasive manner. Intraoperatively, TEE assists the surgeon in deciding whether the operation will extend beyond simple VAD placement, and postoperatively, it serves to monitor device function and myocardial recovery, and assists with weaning efforts and in the differential diagnosis of low-output states. The following should be included in the routine TEE assessment:

\section{Prebypass}

- Tricuspid valve: Tricuspid insufficiency is not uncommon in patients presenting for LVAD implant. Repair of significant tricuspid regurgitation, either with valvuloplasty or with bioprosthetic valve replacement, is indicated and important for preservation of RV function.

- Mitral valve: Mitral stenosis (MS) should be treated with valve replacement with a tissue prosthesis. MS impedes pump filling and results in elevated left atrial pressures, leading to RV dysfunction.

In general, mitral insufficiency does not require treatment. Decompression of the LV with pump activation usually leads to improvement in the degree of regurgitation by 
reducing filling pressures and reducing leaflet tethering that occurs with ventricular dilatation.

Preexisting mitral valve prostheses, whether mechanical or biologic, are generally left alone, keeping in mind that greater degrees of anticoagulation may be required postoperatively.

- Aortic valve: AS does not generally need to be addressed surgically unless there is associated Al. In the presence of hemodynamically significant AS, the LVAD generates most of the systemic output.

With rotary devices, Al may occur throughout the cardiac cycle, leading to high pump flows and an aorto-ventricular-LVAD circuit with wasted flow. Lowering the pump speed can decrease the transvalvular gradient and the amount of regurgitation, but at the expense of systemic perfusion. ${ }^{85}$ Unloading of the LV with device placement can increase the gradient between the aorta and LV, leading to augmentation of the original degree of regurgitation. Moderate-to-severe Al must be surgically managed. This condition can be handled in several ways. Using the "Park stitch" technique, the edges of the aortic cusps can be sewn together to reduce or eliminate $\mathrm{Al}^{86}$ Another option is oversewing the aortic valve or outflow tract, keeping in mind that any device malfunction will certainly prove fatal, because the patient becomes totally device dependent. ${ }^{87}$ Alternatively, the aortic valve can be replaced with a bioprosthesis.

In patients with a preexisting mechanical aortic prosthesis and anticipated longterm mechanical support, the valve should be replaced with a bioprosthesis or oversewn, because of the risk of thromboembolism.

- Intracardiac shunt: An intracardiac shunt (atrial septal defect, patent foramen ovale, ventricular septal defect) must be ruled out. A bubble study using agitated saline 88,89 and color flow Doppler should be used to interrogate the interatrial and interventricular septum. A negative bubble and color flow study may still fail to identify a patent foramen ovale because of elevated left-sided pressures, and these should be repeated postbypass. If a shunt is detected after left-sided decompression, it should be repaired. A Valsalva maneuver can enhance shunt detection, but should be used with caution, because it can provoke significant hemodynamic instability by altering venous return to the right side of the heart.

- Right ventricular function: RV size and function are assessed. This is only a semiquantitative measure. More quantitative measures can be achieved preoperatively with transthoracic echocardiography (TTE) by calculating global right ventricular fractional area of change (RVFAC), which is equal to the difference between RV diastolic and systolic areas divided by the RV diastolic area. ${ }^{90}$ If the RVFAC is less than $20 \%$, patients may be more vulnerable to postoperative RV failure (normal RVFAC $\geq 40 \%$ ). Because LV unloading increases RV preload and can cause a leftward shift of the interventricular septum, RV dysfunction can become unmasked or augmented postbypass.

- Thrombus: All chambers should be checked for the presence of thrombus, although this should never preclude visual inspection. Blood flow stasis can lead to thrombus formation in the left atrial appendage, left atrium, akinetic or aneurysmal ventricular segments, and on central monitoring catheters, pacing, or implantable defibrillator leads.

- Ascending aorta: The aorta should be assessed for the presence of atheromatous disease, particularly at the site of the outflow graft anastomosis. 


\section{Postbypass}

- Inflow cannula position: The inflow cannula should be directed posteriorly, toward the mitral valve (Fig. 5). If it is directed toward the interventricular septum, inflow can be compromised, which can become a problem in the future because the LV size decreases over time. Flow into the inflow cannula should be laminar and unidirectional (Fig. 6). Any amount of turbulence or high Doppler velocities may indicate cannula obstruction by the septum or occlusion by thrombus. Normal peak Doppler velocities are between 0.7 and $2.0 \mathrm{~m} / \mathrm{sec}$ (Fig. 7), depending on preload conditions and native heart function. The inflow cannula position should be rechecked after chest closure. A typical pulse wave Doppler flow trace shows a low-velocity phasic pattern.

- Outflow cannula position: The outflow cannula can be difficult to image (Fig. 8). Using pulse wave Doppler, the sample volume should be approximately $1 \mathrm{~cm}$ proximal to the aortic anastomosis. Normal velocities are approximately $0.5-$ $2.0 \mathrm{~m} / \mathrm{sec}$ (Fig. 9). ${ }^{91}$ These flow velocities depend on pump speed and output, as well as the cannula's angle of insertion. ${ }^{92}$

- Deairing: This procedure should be accomplished before separation from bypass and at low LVAD speeds. Complete filling of the LV is necessary to prevent air aspiration around the inflow conduit.

- Septal position: Septal shift can occur at high pump speeds and with inadequate LV preload. Pump speed is adjusted and preload administered to maintain the septum in a midline position.

- Aortic valve opening: With full pump support, the aortic valve remains closed. Pump speed can be set based on the degree of valve opening.

- Mitral valve: Persistent significant mitral regurgitation may be related to inadequate LV decompression.

- Tricuspid valve: Increasing severity of tricuspid regurgitation can occur at increased pump speeds if there is septal shift with distortion of the tricuspid annulus. This condition can also occur in the presence of RV decompensation, as can occur with a right coronary air embolism. The severity of increasing

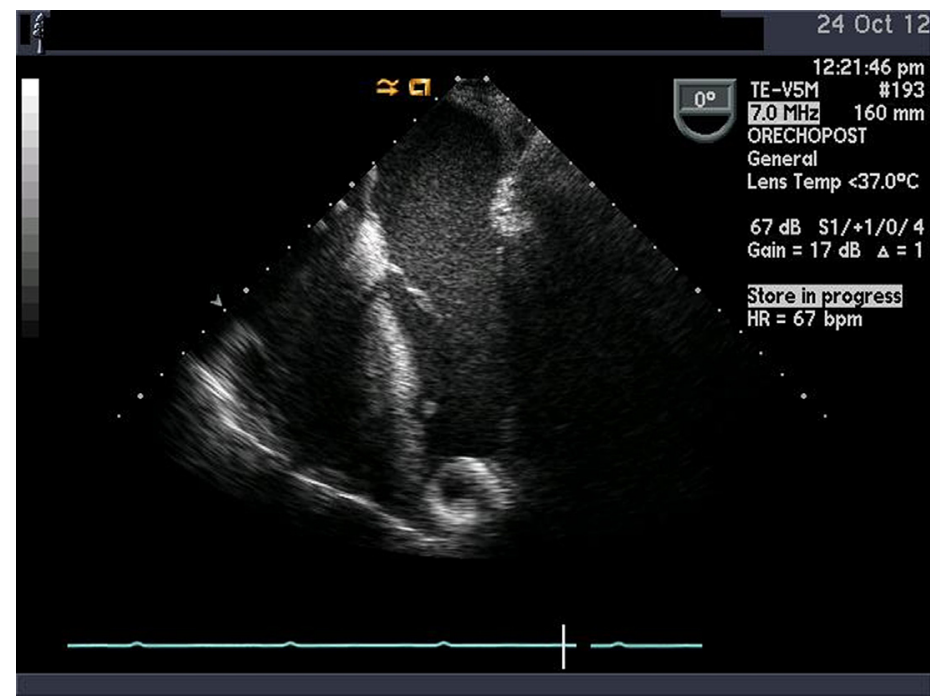

Fig. 5. TEE 4-chamber view showing proper positioning of LV apical inflow cannula. 


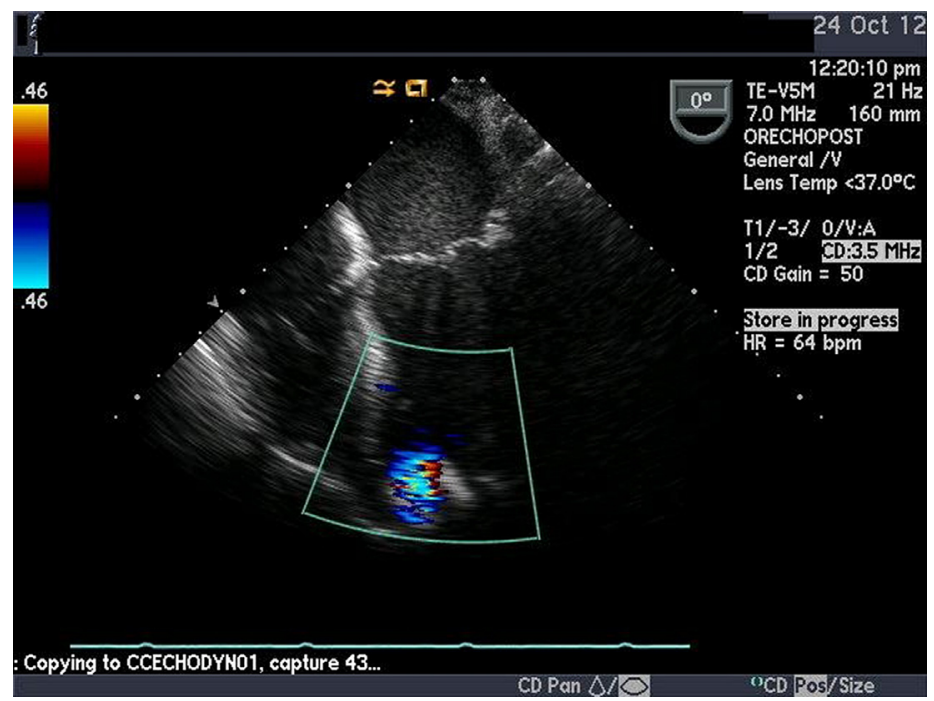

Fig. 6. TEE 4-chamber view with color flow Doppler showing laminar flow in the apical inflow cannula.

tricuspid regurgitation can sometimes be reduced by adjusting the pump speed.

- Right ventricular function: TEE can help determine the need for or response to inotropic support.

- Intracardiac shunt: The lack of intracardiac shunting should be reconfirmed postpump.

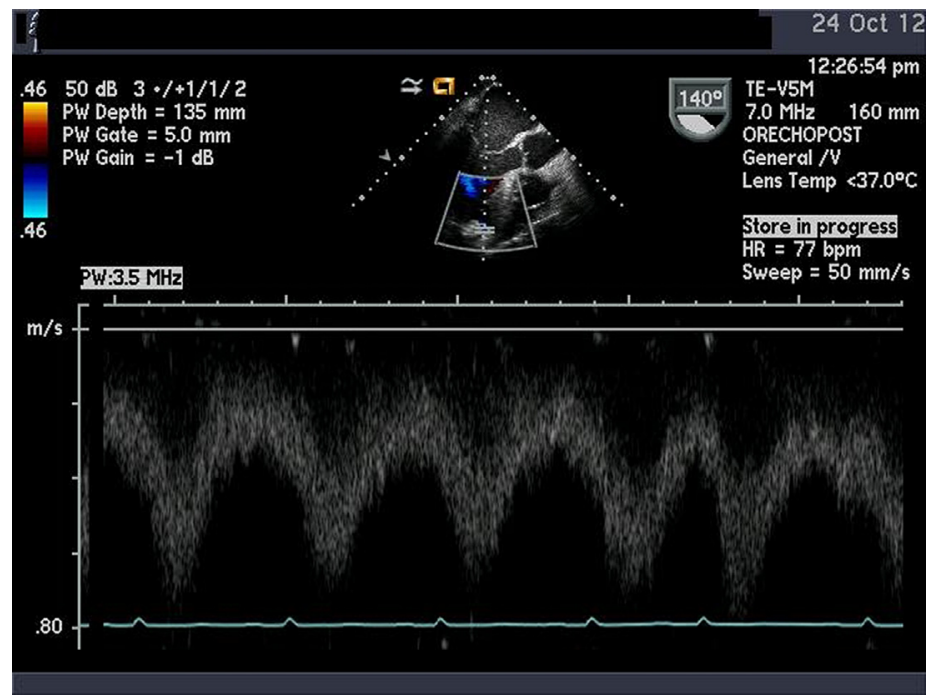

Fig. 7. Pulse wave Doppler of LV apical inflow cannula showing normal velocities (see text) and laminar flow. 


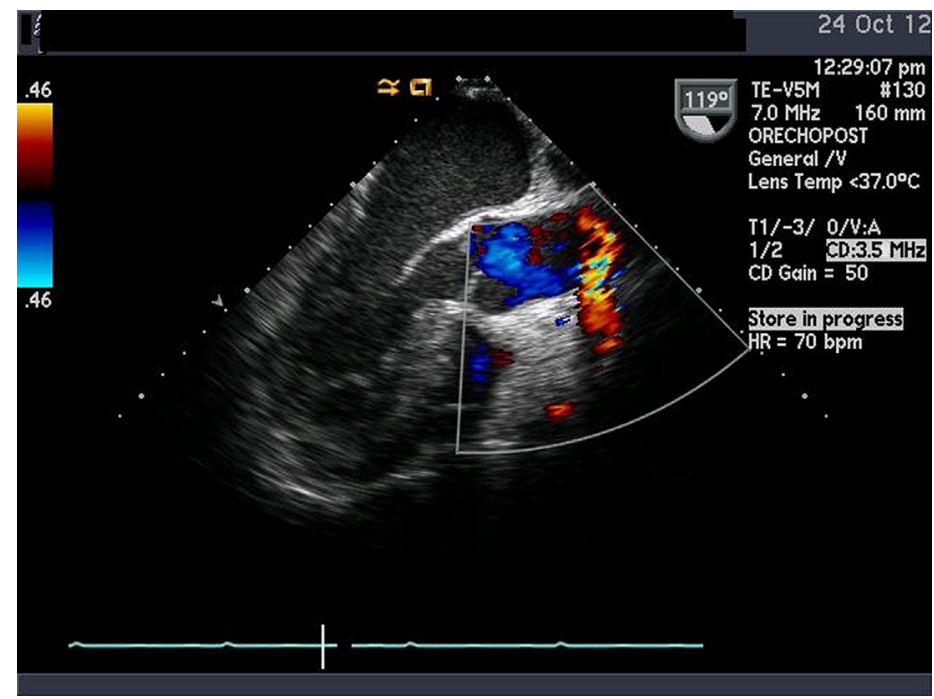

Fig. 8. TEE long-axis view with color flow Doppler showing laminar flow in the aortic outflow cannula.

- Volume status: Low LV volumes can be device or patient related. Hypovolemia and RV failure can lead to reduced LV preload, whereas too high pump speeds can cause LV collapse. High ventricular volumes, as can be seen with inflow cannula obstruction, can lead to rightward shift of the interventricular septum, tethering of the mitral valve leaflets, and functional mitral regurgitation.

Postchest closure, the patient should be reassessed with TEE. Chest closure can lead to deterioration of RV function. Increased peak airway pressures can adversely affect right-sided venous return, and resulting increased pulmonary artery pressures

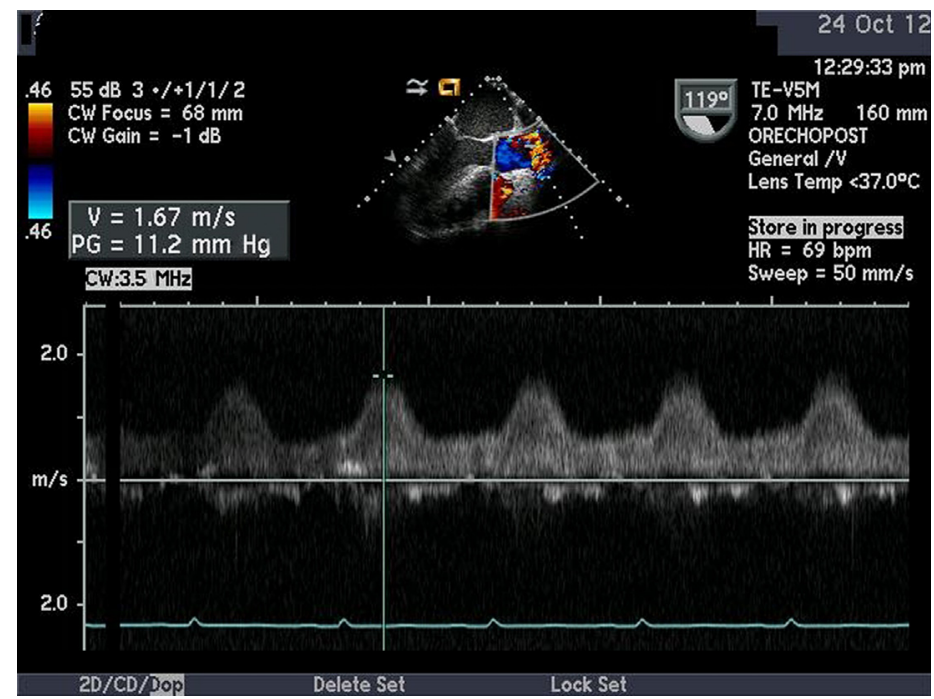

Fig. 9. Pulse wave Doppler of aortic outflow cannula showing normal velocities (see text). 
can have detrimental effects. Inflow cannula position should also be reassessed postchest closure.

\section{Speed Ramp Study}

When the patient is hemodynamically stable, a range of speed settings can be determined using the ramped speed test. ${ }^{93}$ A ramped speed study ${ }^{94}$ allows the operator to determine the range of safe operating pump speeds as follows:

- Determine low-end range: The pump speed is gradually reduced until the aortic valve opens with each beat and the patient shows no signs of cardiac failure. In the absence of aortic valve opening, with the use of a pulmonary artery catheter, the lowest speed setting should occur at a cardiac index of $2.5 \mathrm{~L} / \mathrm{min} / \mathrm{m}^{2}$. Alternatively, TTE can be used to set the low speed cutoff when LV size increases and there is rightward septal shift. The speed should not be set below $8000 \mathrm{rpm}$.

- Determine high-end range: The pump speed is gradually increased until there is septal flattening, there is a decrease in LV end-diastolic dimension, the aortic valve remains closed, and the pulse pressure is 10 to $15 \mathrm{~mm} \mathrm{Hg}$. This speed is generally below $9600 \mathrm{rpm}$.

The proper speed setting will generally occur somewhere between the low and highend speeds.

\section{COMPLICATIONS}

It should be emphasized that proper timing of device implant, along with meticulous patient selection, can help to lessen some of the complications encountered with these devices. Complications have included:

- Bleeding/hemorrhage: Bleeding can be secondary to anticoagulation or hepatic dysfunction or related to the operation itself (especially reoperations).

- Infection and sepsis: Infection remains a prevalent problem in LVAD patients. Device modifications have lowered this risk relative to first-generation LVADs; however, it remains a major cause of morbidity and mortality. Proper patient selection can help lower this risk. Infections can be divided into 3 broad categories: driveline, pump pocket, and LVAD-associated endocarditis. ${ }^{95}$ The driveline is the most common infection site. In addition to device-related factors, pulsatile LVADs have been shown to induce alterations in the recipient's immune system that may contribute to the development of associated infections. These alterations include defects in T-cell function and cellular immunity. ${ }^{96}$ At present, it is unclear if these same changes are seen in axial flow pumps. The newergeneration HeartWare device, which is implanted intrapericardially and has no pump pocket, has a lower device-related infection rate than historical controls, highlighting the contribution of device design to improved infectious outcomes. $^{97}$

- Pump thrombus: Pump thrombus should be suspected when any of the 4 pump parameters are altered. In particular, power values greater than 10 to $12 \mathrm{~W}$, gradual increases in power, or abrupt changes in power are worrisome for pump thrombus. ${ }^{93}$ A developing thrombus can lead to pump flow obstruction. If the thrombus originated upstream and has embolized into the pump, the power increase will be more abrupt. Hemolysis can also be a sign of pump thrombosis.

- Retrograde flow: If the pump stops for any reason (eg, disconnection, power loss), blood can flow retrograde from the aorta to the LV because there are no valves in the circuit. 
- Suction: If the pump speed is set too high in relation to the patient's volume status, LV suction occurs. Several factors can lead to inadequate LV filling, including hypovolemia, RV failure, tamponade, and elevated PVR. When suction is detected, the system is designed to automatically reduce pump speed to the lower set limit in the controller.

- Stroke/Transient ischemic attack

- Hemolysis: This is not a common problem, but can become clinically significant in the presence of pump thrombus.

- Right-sided heart failure: RV dysfunction remains a significant problem postLVAD implant and can occur in up to one-third of patients. ${ }^{71}$ The incidence does not seem to be much different between the HeartMate I and HeartMate II devices, although in a retrospective comparison, fewer patients receiving the HeartMate II required RV assist support or pure inotropic support for RV failure. ${ }^{60}$

- Gl bleeding

- Device failure

\section{TROUBLESHOOTING}

In the postoperative period, several problems can occur, and their source must be identified promptly. Such complications can include:

- Hypovolemia: This can be due to surgical bleeding.

- Tamponade: Postoperatively, this can be due to localized clot formation compressing any or all cardiac chambers. A high index of suspicion is needed to make a prompt diagnosis.

- $R V$ failure: This is seen as a dilated RV with functional tricuspid regurgitation, and low LV volumes with potential intermittent inflow cannula obstruction from suction events.

- Arrhythmias: These can occur as a result of suction events.

- Hypoxemia: An interatrial communication should be ruled out if no other source is identified.

- Pulmonary embolism

- Device-related problems: This includes inflow cannula malposition, outflow cannula kinking, and pump thrombosis.

Echocardiography is indispensable in the diagnosis and management of these types of problems. ${ }^{93,98,99}$ The 4 pump parameters can provide a clue to the cause of pump- or patient-related problems as outlined in Figs. 10 and 11. It can be recalled that pump flow values are only estimates and are based on power. At low and high ends of the power-flow relationship, these estimates are imprecise. Increases in PI can result from increased LV filling and improved myocardial performance. Decreases in PI can be related to reduced LV filling and reduced contractility. Gradual or abrupt increases in power are highly suspect for pump thrombosis. Increases in pump power can be seen with increases in pump speed, with increases in pump flow, and during periods of increased physiologic demand. Close attention should be paid to the position of the interventricular septum, frequency of aortic valve opening, pulsatility, PAP estimates from tricuspid regurgitation Doppler velocities, LVAD output versus total output, and overall volume status. It must be remembered that power increases that are not matched by actual flow increases will lead to falsely elevated estimated flows.

- Low flow, high power: In the presence of low echocardiographically determined flow and high power, pump failure and increased afterload must be ruled out 


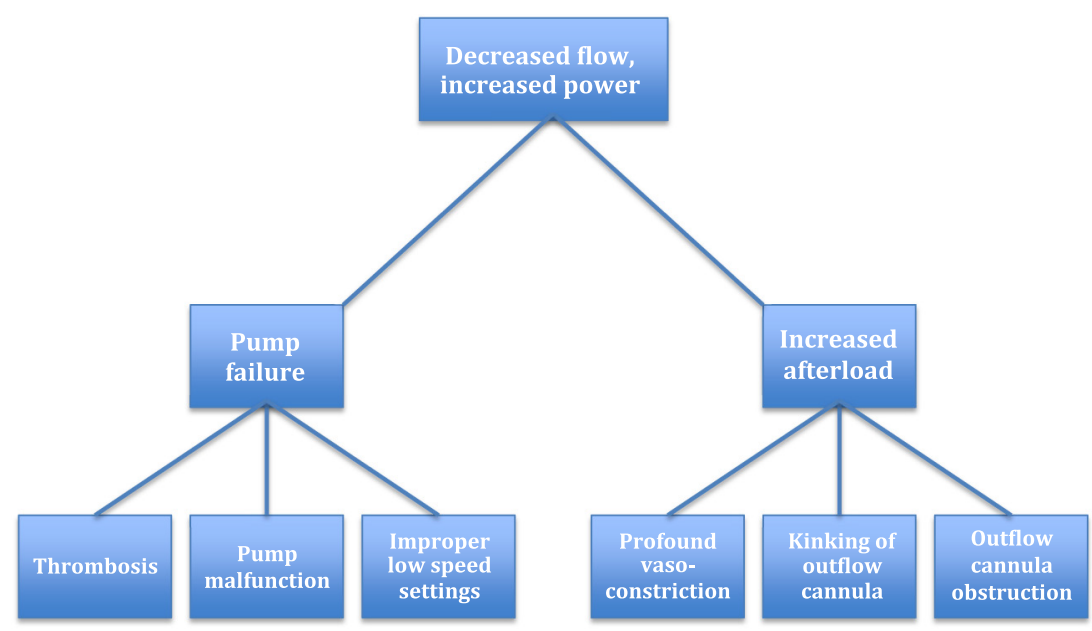

Fig. 10. Algorithm illustrating differential diagnosis of increased pump power and echocardiographically determined decreased flow (output).

(see Fig. 10). Pump failure can be due to thrombosis, malfunction, and improperly set low-speed settings. Echocardiography can show a rightward shift of the interventricular septum, an increase in functional mitral regurgitation, regular opening of the aortic valve, spontaneous echo contrast or "smoke" in the left atrium and/or ventricle, and regurgitation across the LVAD inflow and outflow cannulas. Pump thrombus can increase rotor drag leading to increased power requirement, and the $\mathrm{PI}$ decreases. The presence of hemolysis is also suspicious for pump thrombosis. LVAD thrombosis can be managed with anticoagulation or thrombolysis, whereas pump malfunction may require emergent pump exchange. Because the system contains no valves, any loss of power can potentially lead to retrograde flow. If the impeller fails to rotate, the pump becomes no

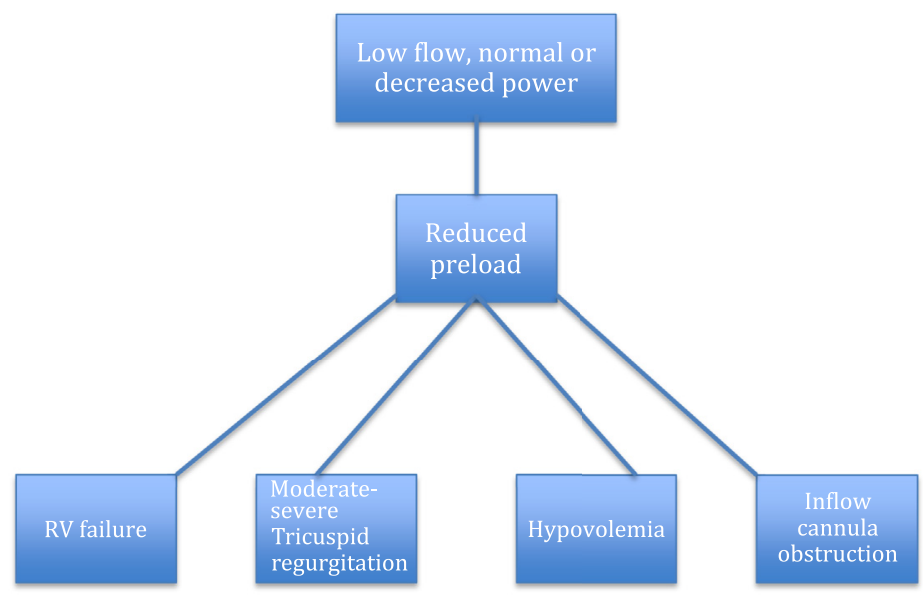

Fig. 11. Algorithm illustrating differential diagnosis of decreased pump power and echocardiographically determined low or normal flow (output). 
more than a conduit between the ventricle and ascending aorta. If diastolic aortic pressure exceeds LV pressure, retrograde flow will ensue.

Elevated systemic vascular resistance will cause the aortic valve to remain closed. The PI is increased in this situation. The outflow cannula shows high-velocity flow (pressure in the LV is elevated) with a pulsatile contour despite reduced pump output. Aortic pressure is higher than ventricular pressure, which keeps the aortic valve closed. Continued rotation of the impeller augments the pressure wave generated by the LV. At low pump speeds and high afterload, retrograde flow can also occur. If there is obstruction of the outflow cannula from thrombus or kinking, LV systolic pressure will be greater than aortic pressure, leading to regular opening of the aortic valve.

Any of the following should alert the clinician to the possibility of pump thrombosis:

- Decreased pump flow

- Opening of the aortic valve with each beat because of increased LV preload

- Rightward septal bowing

- Increased mitral regurgitation from LV dilatation and leaflet tethering

- Hemolysis

- Altered pump parameters, especially increased power

- Low flow, low/normal power: In the presence of low echocardiographically detected flow and low or normal power, decreased preload should be suspected (see Fig. 11). This situation can be due to RV failure, moderate-to-severe tricuspid regurgitation, hypovolemia, and inflow cannula obstruction.

- In the presence of high echocardiographically detected flow with low estimated cardiac output as estimated by echocardiography, Al must be ruled out.

\section{THIRD-GENERATION VENTRICULAR ASSIST DEVICES}

Third-generation LVADs use magnetic and/or hydrodynamic levitation of the impeller, which has eliminated the need for contact bearings. ${ }^{100}$ Third-generation devices include the HeartWare HVAD, which uses hydrodynamic levitation along with magnetic levitation for suspension; the HeartMate III (Thoratec Corporation, Pleasanton, CA, USA), ${ }^{101}$ which uses full magnetic suspension; the Berlin Heart Incor (Berlin Heart AG, Berlin, Germany), and the DuraHeart (Terumo Heart, Inc, Ann Arbor, MI, USA), ${ }^{102,103}$ which uses magnetic levitation. Advantages over previous-generation devices include:

- Smaller size

- Thinner driveline

- Lack of contact bearings

- Lack of pump pocket

- No mechanical wear-and-tear

- Potential for greater durability than previous-generation devices

- Ideal for small patients, including children

- Absence of friction and heat generation

\section{HEARTWARE HVAD}

The HeartWare VAD (HeartWare, Inc, Miami Lakes, FL, USA) is a $140 \mathrm{~g}$ miniaturized implantable centrifugal flow pump with a $50 \mathrm{~mL}$ displacement volume that is implanted in the pericardial space and was introduced clinically in 2006 (Figs. 12-15). ${ }^{104,105}$ This device can generate flows up to $10 \mathrm{~L} / \mathrm{min}$. The wide-blade impeller of this device is 


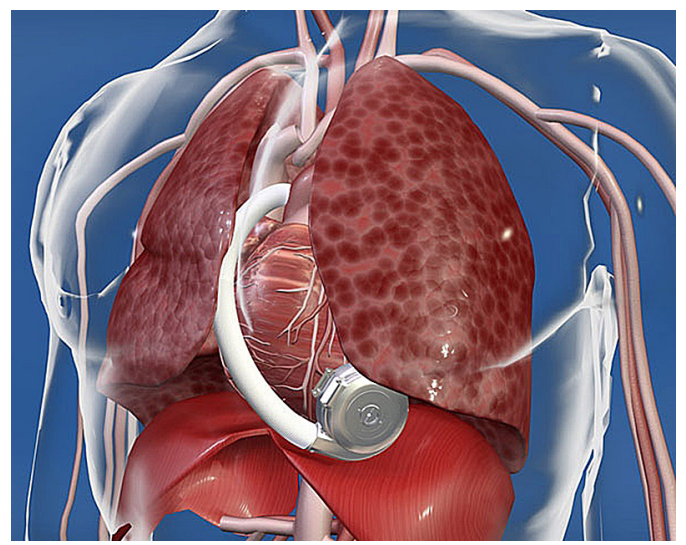

Fig. 12. HeartWare LVAD in situ. (Courtesy of Heartware, Inc, Miami Lakes, FL, USA.)

suspended by hybrid passive magnets and hydrodynamic forces. ${ }^{106}$ Because there are no mechanical contact points within the pump, friction and heat generation have been eliminated and extended durability is expected. The integrated inflow cannula is inserted into the LV apex, and the pump itself is positioned in the pericardial space, eliminating the need for a pump pocket and thereby simplifying the surgical implant. The $10-\mathrm{mm}$ outflow graft, made of zero porosity gelatin-impregnated

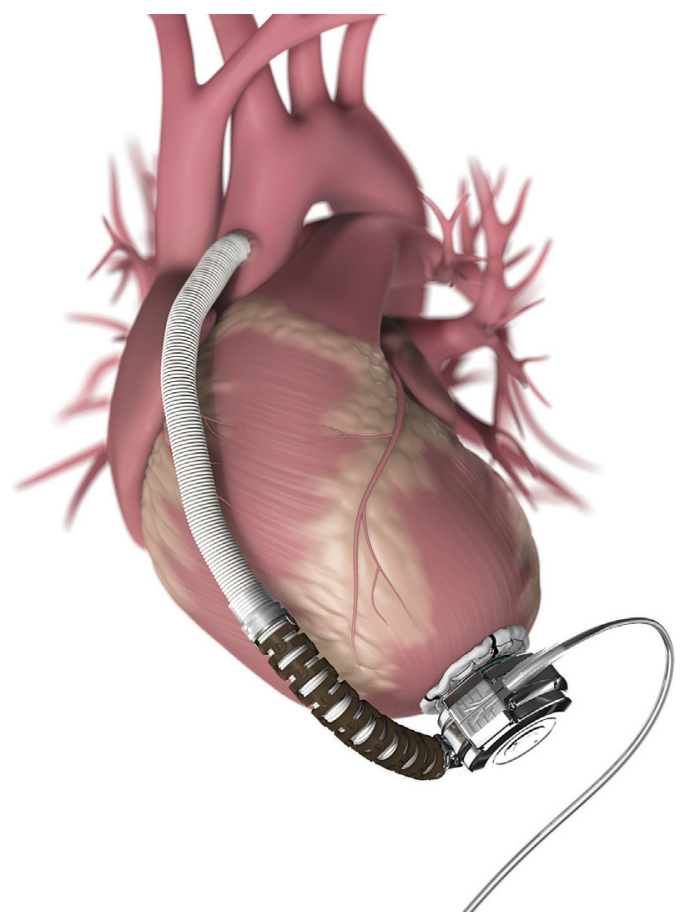

Fig. 13. HeartWare LVAD in situ showing LV apical (pericardial) location of pump. (Courtesy of Heartware, Inc, Miami Lakes, Florida.) 


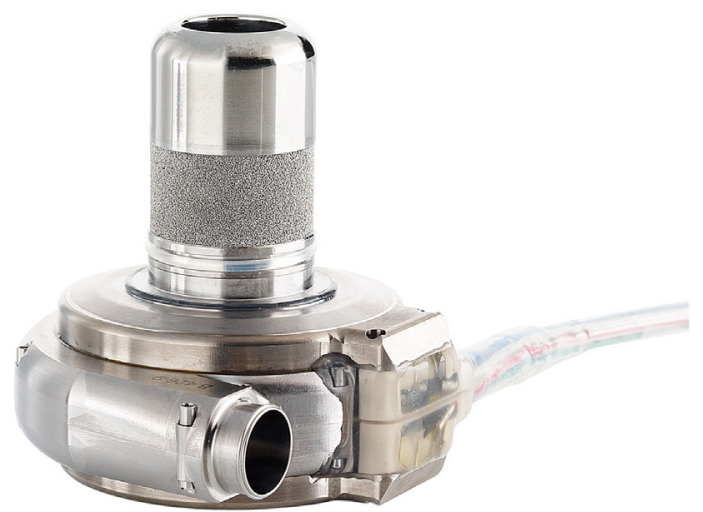

Fig. 14. Miniaturized HeartWare HVAD pump. (Courtesy of Heartware, Inc, Miami Lakes, FL, USA.)

material, is anastomosed to the ascending aorta. ${ }^{107,108}$ Although it is intended for LV support, biventricular support has been reported. ${ }^{109}$

\section{Components}

- Front housing: The front housing includes the integrated 25-mm-long titanium inflow cannula.

- Rear housing: The rear housing includes a center post with a magnetic stack corresponding to a similar stack found within the impeller, which develops a strong repulsive force that helps to maintain the impeller's radial support. The center post's magnetic stack is vertically aligned and shifted downward relative to the impeller's magnetic stack. This position in turn creates an axial magnetic force that maintains the impeller position toward the front housing.

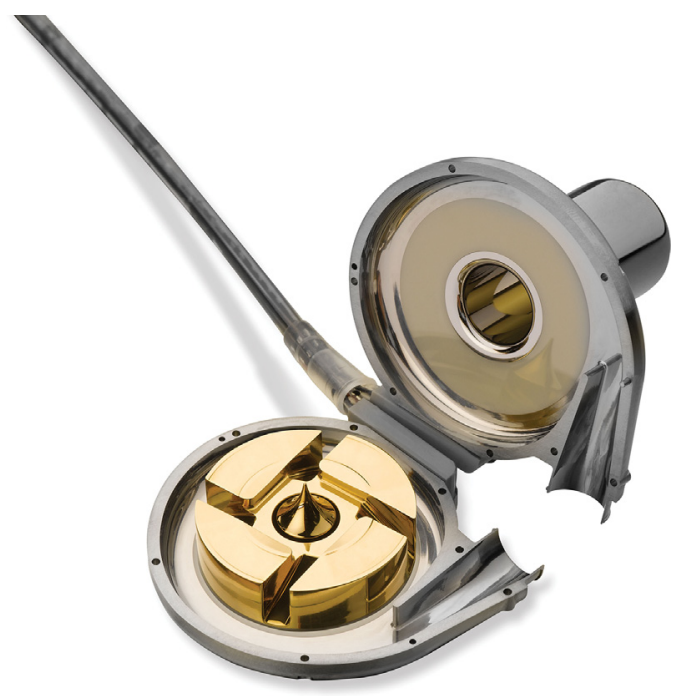

Fig. 15. Internal view of HeartWare HVAD showing impeller. (Courtesy of Heartware, Inc, Miami Lakes, FL, USA.) 
- Rotating impeller: The rotating impeller has wide blades and accommodates 4 large rare-earth magnets, contributing to the pump's high efficiency. The impeller suspension system includes a separate stack of 3 rare earth magnets with like poles.

- Outflow graft: The 10-mm outflow graft is made of Vascutek Gelweave (Terumo Cardiovascular Systems Corp, Ann Arbor, MI, USA), which is a gelatinimpregnated graft material with zero porosity. Graft kinking is prevented by the inclusion of an articulating strain relief in the proximal portion. This strain relief consists of plastic interlocking vertebra links.

- Driveline cable: The driveline measures only $4.2 \mathrm{~mm}$ in diameter and is made up of 6 insulated fatigue-resistant cables. Woven Dacron polyester covers portions of the driveline cable to facilitate tissue ingrowth at the exit site.

- Microprocessor-based controller: The controller is connected to the pump via the percutaneous driveline. The controller operates the pump and monitors its function, provides diagnostic information, stores data, and manages the different available power sources (AC, DC, and battery power). Two separate power sources must be connected at all times.

\section{Pump Operation}

When the pump is activated, the impeller begins to rotate. The hydrodynamic thrust bearings push the impeller away from the front housing. The impeller is separated from the front housing by a blood barrier. Blood is forced through the pump by the rotating impeller using hydrodynamic and centrifugal forces. The electromagnetic coupling between motor magnets within the impeller and motor stators in the front and rear housings provide rotational energy to the impeller. Blood flow through the pump at a constant rotational speed (range 1800-4000 rpm) depends on the differential pressure across the pump. This system is a preload- and afterload-dependent one, and the difference between LV and aortic pressures is the most important determinant of flow through the pump. The lower the pressure differential, the higher is the flow rate generated. The highest flow rates occur under conditions of increased preload and decreased afterload, regardless of the impeller speed. Estimated flow is calculated from the pump speed, motor current, and blood viscosity (adjusted based on hematocrit), and baseline flow must exceed $1.8 \mathrm{~L} / \mathrm{min}$ to prevent suction.

\section{The ADVANCE Trial}

The ADVANCE trial is a US nonrandomized multicenter study that enrolled 140 patients listed for transplant to receive the new HeartWare HVAD. ${ }^{110}$ Results at 180 days were compared with data from 499 patients of the INTERMACS registry who had received an LVAD (mostly HeartMate II) as a bridge to transplant. Results from this study suggested that the HeartWare is at least as good as the currently available devices.

The primary outcome in this study was survival on the originally implanted HVAD, transplant, or explant (with 60-day postexplant survival) at 180 days. Secondary outcomes included comparison of survival between treatment groups and INTERMACS controls, functional outcomes, quality of life outcomes, and adverse events in the HVAD group. Patients in the HVAD group had 92\% (compared with $90.1 \%$ in the control group, $P<.001)$ success with regard to the primary outcome, the highest rate reported to date at 180 days with any type of VAD as a bridge to transplant.

Although less bleeding and infection were observed, stroke was a concerning adverse event. As with second-generation devices, Gl bleeding from arteriovenous malformations was also seen. 


\section{Endurance Trial}

The Endurance Trial is currently underway and is a randomized controlled unblinded multicenter comparison of the HeartWare HVAD with the HeartMate II as destination therapy in nontransplant candidates. This study will enroll 450 patients at 50 US hospitals.

\section{SUMMARY}

The evolution of mechanical circulatory support devices from large pulsatile pumps to smaller axial and centrifugal flow devices has dramatically altered the course of patients with advanced heart failure. Greater durability and lower complication rates have enhanced survival and quality of life. In select patients, destination therapy may result in survival rates comparable to transplant recipients. ${ }^{111}$ At present, 2-year unadjusted survival after transplant is around $80 \% .{ }^{112}$ Using survival metrics based on this unadjusted survival in bridge-to-transplant transplant recipients, Kirklin and colleagues ${ }^{111}$ have suggested that subsets of destination therapy patients might achieve comparable outcomes over this same time period. At present, nearly onethird of LVAD recipients are destination therapy patients. With little anticipated change in transplant donor availability, it can be expected that mechanical circulatory support will continue to be a viable alternative in transplant-eligible patients. Based on some of the promising results seen with the newer third-generation pumps, it is anticipated that they will receive FDA approval in the near future.

\section{REFERENCES}

1. Reich DJ, Mulligan DC, Abt PL, et al. ASTS recommended practice guidelines for controlled donation after cardiac death organ procurement and transplantation. Am J Transplant 2009;9:2004-11.

2. Ali AA, White $P$, Xiang $B$, et al. Hearts from DCD donors display acceptable biventricular function after heart transplantation in pigs. Am J Transplant 2011; 11:1621-32.

3. Stehlik J, Edwards LB, Kucheryavaya AY, et al. The Registry of the International Society for Heart and Lung Transplantation: twenty-seventh official adult heart transplant report-2010. J Heart Lung Transplant 2010;29:1089-103.

4. Rose EA, Gelijns AC, Moskowitz AJ, et al. Long-term use of a left ventricular assist device for end-stage heart failure. N Engl J Med 2001;345:1435-43.

5. Slaughter MS, Rogers JG, Milano CA, et al. Advanced heart failure treated with continuous-flow left ventricular assist device. N Engl J Med 2009;361: 2241-51.

6. Lietz K, Deng M, Morgan J, et al. Selection of UNOS status 1A candidates for mechanical circulatory support as bridge-to-transplantation (BTT)—Analysis of UNOS/OPTN 2000-2005. J Heart Lung Transplant 2008;27(2S):S244.

7. Zimpfer D, Zrunek P, Roethy W, et al. Left ventricular assist devices decrease fixed pulmonary hypertension in cardiac transplant candidates. J Thorac Cardiovasc Surg 2007;133:689-95.

8. Frazier $\mathrm{OH}$, Benedict $\mathrm{CR}$, Radovancevic B, et al. Improved left ventricular function after chronic ventricular unloading. Ann Thorac Surg 1996;62:675-81.

9. Dandel M, Weng $\mathrm{Y}$, Siniawski $\mathrm{H}$, et al. Long-term results in patients with idiopathic dilated cardiomyopathy after weaning from left ventricular assist devices. Circulation 2005;112(Suppl I):I37-45. 
10. Simon MA, Kormos RL, Murali S, et al. Myocardial recovery using ventricular assist devices: prevalence, clinical characteristics, and outcomes. Circulation 2005;112:I32-6.

11. Mancini DM, Beniaminovitz A, Levin $\mathrm{H}$, et al. Low incidence of myocardial recovery after left ventricular assist device implantation in patients with chronic heart failure. Circulation 1998;98:2383-9.

12. Klotz S, Danser AH, Burkhoff D. Impact of left ventricular assist device (LVAD) support on the cardiac reverse remodeling process. Prog Biophys Mol Biol 2008;97:479-96.

13. Maybaum S, Mancini D, Xydas S, et al. Cardiac improvement during mechanical circulatory support: a prospective multicenter study of the LVAD Working Group. Circulation 2007;115:2497-505.

14. Birks EJ, Tansley PD, Hardy J, et al. Left ventricular assist device and drug therapy for the reversal of heart failure. N Engl J Med 2006;355:1873-84.

15. George RS, Yacoub MH, Bowles CT, et al. Quality of life after removal of left ventricular assist device for myocardial recovery. J Heart Lung Transplant 2008;27:165-72.

16. Birks EJ, George RS, Hedger M, et al. Reversal of severe heart failure with a continuous-flow left ventricular assist device and pharmacological therapy: a prospective study. Circulation 2011;123:381-90.

17. Wong K, Boheler K, Petrou M, et al. Pharmacological modulation of pressureoverload cardiac hypertrophy: changes in ventricular function, extracellular matrix and gene expression. Circulation 1997;96:2239-46.

18. Wong K, Boheler KR, Bishop J, et al. Clenbuterol induces cardiac hypertrophy with normal functional, morphological, and molecular features. Cardiovasc Res 1998;37:115-22.

19. Lietz K, Long JW, Kfoury AG, et al. Outcomes of left ventricular assist device implantation as destination therapy in the post-REMATCH era: implications for patient selection. Circulation 2007;116:497-505.

20. Higgins J, Lamarche Y, Kaan A, et al. Microaxial devices for ventricular failure: a multicentre, population-based experience. Can J Cardiol 2011;27:725-30.

21. Bruckner BA, Jacob LP, Gregoric ID, et al. Clinical experience with the TandemHeart percutaneous ventricular assist device as a bridge to cardiac transplantation. Tex Heart Inst J 2008;35:447-50.

22. Marasco SF, Lukas G, McDonald M, et al. Review of ECMO (extra corporeal membrane oxygenation) support in critically ill adult patients. Heart Lung Circ 2008;17(Suppl 4):S41-7.

23. Park SJ, Tector A, Piccioni W, et al. Left ventricular assist devices as destination therapy: a new look at survival. J Thorac Cardiovasc Surg 2005;129:9-17.

24. Rogers JG, Butler J, Lansman SL, et al. Chronic mechanical circulatory support for inotrope-dependent heart failure patients who are not transplant candidates: results of the INTrEPID Trial. J Am Coll Cardiol 2007;50:741-7.

25. Holman WL, Pae WE, Teuteberg JJ, et al. INTERMACS: interval analysis of registry data. J Am Coll Surg 2009;208:755-61.

26. Kirklin JK, Naftel DC, Kormos RL, et al. The fourth INTERMACS annual report: 4000 implants and counting. J Heart Lung Transplant 2012;31:117-26.

27. Stevenson LW, Pagani FD, Young JB, et al. INTERMACS profiles of advanced heart failure: the current picture. J Heart Lung Transplant 2009;28:535-41.

28. Lietz K, Miller LW. Patient selection for left-ventricular assist devices. Curr Opin Cardiol 2009;24:246-51. 
29. Alba AC, Rao V, Ivanov J, et al. Usefulness of the INTERMACS scale to predict outcomes after mechanical assist device implantation. J Heart Lung Transplant 2009;28:827-33.

30. Teuteberg JJ, Ewald GA, Adamson RM, et al. Risk assessment for continuous flow left ventricular assist devices: does the destination therapy risk score work? An analysis of over 1000 patients. J Am Coll Cardiol 2012;60:44-51.

31. Matthews JC, Koelling TM, Pagani FD, et al. The right ventricular failure risk score: a preoperative tool for assessing the risk of right ventricular failure in left ventricular assist device candidates. J Am Coll Cardiol 2008;51:2163-72.

32. Potapov EV, Loebe M, Nasseri BA, et al. Pulsatile flow in patients with a novel nonpulsatile implantable ventricular assist device. Circulation 2000;102(19 Suppl 3): III183-7.

33. John R. Current axial-flow devices: the HeartMate II and Jarvik 2000 left ventricular assist devices. Semin Thorac Cardiovasc Surg 2008;20:264-72.

34. Thalmann M, Schima H, Wieselthaler G, et al. Physiology of continuous blood flow in recipients of rotary cardiac assist devices. J Heart Lung Transplant 2005;24:237-45.

35. OOtaki C, Yamashita M, OOtaki Y, et al. Reduced pulsatility induces periarteritis in kidney: role of local renin-angiotensin system. J Thorac Cardiovasc Surg 2008;136:150-8.

36. Nishimura T, Tatsumi E, Takaichi S, et al. Prolonged nonpulsatile left heart bypass with reduced systemic pulse pressure causes morphological changes in the aortic wall. Artif Organs 1998;22:405-10.

37. Kihara S, Litwak KN, Nichols L, et al. Smooth muscle cell hypertrophy of renal cortex arteries with chronic continuous flow left ventricular assist. Ann Thorac Surg 2003;75:178-83.

38. Frazier $\mathrm{OH}$, Myers TJ, Westaby S, et al. Use of the Jarvik 2000 left ventricular assist system as a bridge to heart transplantation or as destination therapy for patients with chronic heart failure. Ann Surg 2003;237:631-6.

39. Mudd JO, Cuda JD, Halushka M, et al. Fusion of aortic valve commissures in patients supported by a continuous axial flow left ventricular assist device. J Heart Lung Transplant 2008;27:1269-74.

40. Tominaga R, Smith WA, Massiello A, et al. Chronic non-pulsatile blood flow. I. Cerebral autoregulation in chronic nonpulsatile biventricular bypass: carotid blood flow response to hypercapnia. J Thorac Cardiovasc Surg 1994;108: 907-12.

41. Letsou GV, Shah N, Gregoric ID, et al. Gastrointestinal bleeding from arteriovenous malformations in patients supported by the Jarvik 2000 axial flow left ventricular assist device. J Heart Lung Transplant 2005;24:105-9.

42. Stern DR, Kazam J, Edwards $P$, et al. Increased incidence of gastrointestinal bleeding following implantation of the HeartMate II LVAD. J Card Surg 2010; 25:352-6.

43. Pate GE, Mulligan A. An epidemiological study of Heyde's syndrome: an association between aortic stenosis and gastrointestinal bleeding. J Heart Valve Dis 2004;13:713-6.

44. Heyde EC. Gastrointestinal bleeding in aortic stenosis [Letter to the editor]. N Engl J Med 1958;259:196.

45. Singh P, Scoyni R, Pooran N, et al. Aortic valve replacement: a last resort for aortic stenosis-associated refractory Gl bleeding. Gastrointest Endosc 2002; 56:139-41. 
46. Warkentin TE, Moore JC, Morgan DG. Aortic stenosis and bleeding gastrointestinal angiodysplasia: is acquired von Willebrand's disease the link? Lancet 1992; 340:35-7.

47. Vincentelli A, Susen S, Le Tourneau T, et al. Acquired von Willebrand syndrome in aortic stenosis. N Engl J Med 2003;349:343-9.

48. Geisen U, Heilmann C, Beyersdorf F, et al. Nonsurgical bleeding in patients with ventricular assist devices could be explained by acquired von Willebrand disease. Eur J Cardiothorac Surg 2008;33:679-84.

49. Klovaite J, Gustafsson F, Mortensen SA, et al. Severely impaired von Willebrand factor-dependent platelet aggregation in patients with a continuous-flow left ventricular assist device (HeartMate II). J Am Coll Cardiol 2009;53:2162-7.

50. Cappell MS, Lebwohl O. Cessation of recurrent bleeding from gastrointestinal angiodysplasias after aortic valve replacement. Ann Intern Med 1986;105:54-7.

51. Meyer AL, Malehsa D, Bara C, et al. Acquired von Willebrand syndrome in patients with an axial flow left ventricular assist device. Circ Heart Fail 2010;3: 675-81.

52. Boyle AJ, Russell SD, Teuteberg JJ, et al. Low thromboembolism and pump thrombosis with the HeartMate II left ventricular assist device: analysis of outpatient anti-coagulation. J Heart Lung Transplant 2009;28:881-7.

53. Miller LW, Pagani FD, Russell SD, et al. Use of a continuous-flow device in patients awaiting heart transplantation. N Engl J Med 2007;357:885-96.

54. Griffith BP, Kormos RL, Borovetz HS, et al. HeartMate II left ventricular assist system: from concept to first clinical use. Ann Thorac Surg 2001;71(Suppl 3): S116-20.

55. Khalil HA, Cohn WE, Metcalfe RW, et al. Preload sensitivity of the Jarvik 2000 and HeartMate II left ventricular assist devices. ASAIO J 2008;54:245-8.

56. Mano A, Fujita K, Uenomachi K, et al. Body mass index is a useful predictor of prognosis after left ventricular assist system implantation. J Heart Lung Transplant 2009;28:428-33.

57. Holdy K, Dembitsky W, Eaton LL, et al. Nutrition assessment and management of left ventricular assist device patients. J Heart Lung Transplant 2005;24:1690-6.

58. Farrar DJ, Compton PG, Hershon JJ, et al. Right heart interaction with the mechanically assisted left heart. World J Surg 1985;9:89-102.

59. Santamore WP, Gray LA Jr. Left ventricular contributions to right ventricular systolic function during LVAD support. Ann Thorac Surg 1996;61:350-6.

60. Patel ND, Weiss ES, Schaffer J, et al. Right heart dysfunction after left ventricular assist device implantation: a comparison of the pulsatile HeartMate I and axialflow HeartMate II devices. Ann Thorac Surg 2008;86:832-40.

61. Kormos RL, Teuteberg JJ, Pagani FD, et al. Right ventricular failure in patients with the HeartMate II continuous-flow left ventricular assist device: incidence, risk factors, and effect on outcomes. J Thorac Cardiovasc Surg 2010;139: 1316-24.

62. Sandner SE, Zimpfer D, Zrunek P, et al. Renal function and outcome after continuous flow left ventricular assist device implantation. Ann Thorac Surg 2009;87: 1072-8.

63. Kormos RL, Teuteberg JJ, Siegenthaler MP, et al. Pre-VAD implant risk factors influence the onset of adverse events (AEs) while on VAD [abstract]. J Heart Lung Transplant 2009;28:S153-4.

64. Feussner M, Mukherjee C, Garbade J, et al. Anaesthesia for patients undergoing ventricular assist-device implantation. Best Pract Res Clin Anaesthesiol 2012;26:167-77. 
65. Nussmeier NA, Probert CB, Hirsch D, et al. Anesthetic management for implantation of the Jarvik 2000 left ventricular assist system. Anesth Analg 2003;97:964-71.

66. Broussard D, Donaldson E, Falterman J, et al. Anesthesia for left ventricular assist device insertion: a case series and review. Ochsner J 2011;11:70-7.

67. Stone ME. Current status of mechanical circulatory assistance. Semin Cardiothorac Vasc Anesth 2007;11:185-204.

68. Thinberg CA, Gaitan BD, Arabia FA, et al. Ventricular assist devices today and tomorrow. J Cardiothorac Vasc Anesth 2010;24:656-80.

69. Kavarana MN, Pessin-Minsley MS, Urtecho J, et al. Right ventricular dysfunction and organ failure in left ventricular assist device recipients: a continuing problem. Ann Thorac Surg 2002;73:745-50.

70. Deng MC, Edwards LB, Hertz MI, et al. Mechanical circulatory support device database of the International Society for Heart and Lung Transplantation: Third Annual Report-2005. J Heart Lung Transplant 2005;24:1182-7.

71. Dang NC, Topkara VK, Mercando M, et al. Right heart failure after left ventricular assist device implantation in patients with chronic congestive heart failure. J Heart Lung Transplant 2006;25:1-6.

72. Fukamachi K, McCarthy PM, Smedira NG, et al. Preoperative risk factors for right ventricular failure after implantable left ventricular assist device insertion. Ann Thorac Surg 1999;68:2181-4.

73. Kormos RL, Gasior TA, Kawai A, et al. Transplant candidate's clinical status rather than right ventricular function defines need for univentricular versus biventricular support. J Thorac Cardiovasc Surg 1996;111:773-82.

74. Ochiai Y, McCarthy PM, Smedira NG, et al. Predictors of severe right ventricular failure after implantable left ventricular assist device insertion: analysis of 245 patients. Circulation 2002;106(12 Suppl I):I198-202.

75. Nakatani A, Thomas JD, Savage RM, et al. Prediction of right ventricular dysfunction after left ventricular assist device implantation. Circulation 1996; 94(Suppl 9):II216-21.

76. De Wet CJ, Affleck DG, Jacobsohn E, et al. Inhaled prostacyclin is safe, effective, and affordable in patients with pulmonary hypertension, right heart dysfunction, and refractory hypoxemia after cardiothoracic surgery. J Thorac Cardiovasc Surg 2004;127:1058-67.

77. Oz MC, Argenziano M, Catanese KA, et al. Bridge experience with long-term implantable left ventricular assist devices: are they an alternative to transplantation? Circulation 1997;95:1844-52.

78. Salzberg SP, Lachat ML, Zund G, et al. Left ventricular assist device (LVAD) enables survival during $7 \mathrm{~h}$ of sustained ventricular fibrillation. Eur $\mathrm{J}$ Cardiothorac Surg 2004;26:444-6.

79. Argenziano M, Choudhri AF, Oz MC, et al. A prospective randomized trial of arginine vasopressin in the treatment of vasodilatory shock after left ventricular assist device placement. Circulation 1997;96(Suppl 9):II286-90.

80. Maslow AD, Stearns G, Butala P, et al. The hemodynamic effects of methylene blue when administered at the onset of cardiopulmonary bypass. Anesth Analg 2006;103:2-8.

81. Potapov EV, Pasic M, Bauer M, et al. Activated recombinant factor VII for control of diffuse bleeding after implantation of ventricular assist device. Ann Thorac Surg 2002; 74:2182-3.

82. Heise D, Brauer A, Quintel M. Recombinant activated factor VII (Novo7) in patients with ventricular assist devices: case report and review of the current literature. J Cardiothorac Surg 2007;2:47. 
83. Bruckner BA, DiBardino DJ, Ning Q, et al. High incidence of thromboembolic events in left ventricular assist device patients treated with recombinant activated factor VII. J Heart Lung Transplant 2009;28:785-90.

84. Banchis JE, Dawn B, Abdel-Latif A, et al. Acquired aortic cusp fusion after chronic left ventricular assist device support. J Am Soc Echocardiogr 2006; 19:1401.e1-3.

85. Haghi D, Suselbeck T, Saur J. Aortic regurgitation during left ventricular assist device support. J Heart Lung Transplant 2007;26:1220-1.

86. Park SJ, Liao KK, Segurola R, et al. Management of aortic insufficiency in patients with left ventricular assist devices: a simple coaptation stitch method (Park's stitch). J Thorac Cardiovasc Surg 2004;127:264-6.

87. Stringham JC, Bull DA, Karwande SV. Patch closure of the aortic anulus in a recipient of a ventricular assist device. J Thorac Cardiovasc Surg 2000;119: 1293-4.

88. Marriott K, Manins V, Forshaw A, et al. Detection of right-to-left atrial communication using agitated saline contrast imaging: experience with 1162 patients and recommendations for echocardiography. J Am Soc Echocardiogr. Available at: http://dx.doi.org/10.1016/j.echo.2012.09.007. Accessed October, 2012.

89. Lynch JJ, Schuchard GH, Gross CM, et al. Prevalence of right-to-left atrial shunting in a healthy population: detection by Valsalva maneuver contrast echocardiography. Am J Cardiol 1984;53:1478-80.

90. Scalia GM, McCarthy PM, Savage RM, et al. Clinical utility of echocardiography in the management of implantable ventricular assist devices. J Am Soc Echocardiogr 2000;13:754-63.

91. Catena E, Milazzo F, Merli M, et al. Echocardiographic evaluation of patients receiving a new left ventricular assist device: the Impella® Recover 100. Eur J Echocardiogr 2004;5:430-7.

92. May-Newman KD, Hillen BK, Sironda CS, et al. Effect of LVAD outflow conduit insertion angle on flow through the native aorta. J Med Eng Technol 2004;28: 105-9.

93. Topilsky Y, Maltais S, Oh JK, et al. Focused review on transthoracic echocardiographic assessment of patients with continuous axial flow left ventricular assist devices. Cardiol Res Pract 2011;2011:187434.

94. Slaughter MS, Pagani FD, Rogers JG, et al. Clinical management of continuousflow left ventricular assist devices in advanced heart failure. J Heart Lung Transplant 2010;29(Suppl 4):S1-39.

95. Maniar S, Kondareddy S, Topkara VK. Left ventricular assist devicerelated infections: past, present, and future. Expert Rev Med Devices 2011;8: 627-34.

96. Ankersmit HJ, Edwards NM, Schuster M, et al. Quantitative changes in T-cell populations after left ventricular assist device implantation: relationship to T-cell apoptosis and soluble CD95. Circulation 1999;100(Suppl 19):II211-5.

97. Aaronson KD, Slaughter MS, Miller LW, et al. Use of an intrapericardial, continuous-flow, centrifugal pump in patients awaiting heart transplantation. Circulation 2012;125:3191-200.

98. Catena E, Milazzo F, Montorsi E, et al. Left ventricular support by axial flow pump: the echocardiographic approach to device malfunction. J Am Soc Echocardiogr 2005;18:1422.e7-e13.

99. Estep JD, Stainback RF, Little SH, et al. The role of echocardiography and other imaging modalities in patients with left ventricular assist devices. J Am Coll Cardiol 2010;3:1049-64. 
100. Hoshi H, Shinshi T, Takatani S. Third-generation blood pumps with mechanical noncontact magnetic bearings. Artif Organs 2006;30:324-38.

101. Farrar DJ, Bourque K, Dague CP, et al. Design features, developmental status, and experimental results with the HeartMate III centrifugal left ventricular assist system with a magnetically levitated rotor. ASAIO J 2007;53:310-5.

102. Nojiri C, Kijima T, Maekawa J, et al. Development status of Terumo implantable left ventricular assist system. Artif Organs 2001;25:411-3.

103. Morshuis M, El-Banayosy A, Arusoglu L, et al. European experience with DuraHeart magnetically levitated centrifugal left ventricular assist system. Eur J Cardiothorac Surg 2009;35:1020-7.

104. Slaughter MS, Sobieski MA II, Tamez D, et al. HeartWare miniature axial-flow ventricular assist device: design and initial feasibility test. Tex Heart Inst $J$ 2009;36:12-6.

105. Tuzun E, Roberts K, Cohn WE, et al. In vivo evaluation of the HeartWare centrifugal ventricular assist device. Tex Heart Inst J 2007;34:406-11.

106. LaRose J, Tamez D, Ashenuga M, et al. Design concepts and principle of operation of the HeartWare ventricular assist system. ASAIO J 2010;56:285-9.

107. Strueber M, O'Driscoll G, Jansz P, et al. Multicenter evaluation of an intrapericardial left ventricular assist system. J Am Coll Cardiol 2011;57:1375-82.

108. Wieselthaler GM, O'Driscoll G, Jansz P, et al. Initial clinical experience with a novel left ventricular assist device with a magnetically levitated rotor in a multi-institutional trial. J Heart Lung Transplant 2010;29:1218-25.

109. Hetzer R, Krabatsch T, Stepanenko A, et al. Long-term biventricular support with the HeartWare implantable continuous flow pump. J Heart Lung Transplant 2010;29:822-4.

110. Aaronson KD, Slaughter MS, McGee E, et al. Evaluation of the HeartWare ${ }^{\circledR}$ HVAD left ventricular assist system for the treatment of advanced heart failure: results of the ADVANCE Bridge to Transplant Trial [abstract]. Circulation 2010; 122:2215-26.

111. Kirklin JK, Naftel DC, Pagani FD, et al. Long-term mechanical circulatory support (destination therapy): on track to compete with heart transplantation? J Thorac Cardiovasc Surg 2012;144:584-603.

112. Stehlik J, Edwards LB, Kucheryavaya AY, et al. The Registry of the International Society for Heart and Lung Transplantation: Twenty-eighth Adult Heart Transplant Report-2011. J Heart Lung Transplant 2011;30:1078-94. 